$$
\begin{aligned}
& \text {, } \\
& \text { The submutied manuarot thes been } \\
& \text { thered by a convactor of Tho U. }
\end{aligned}
$$

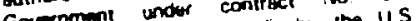

$$
\begin{aligned}
& \text { CONF-880) Ko--1-Vugraph S- }
\end{aligned}
$$

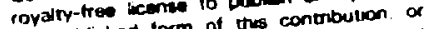
the oublintided tom of US. Govermment

\title{
LONG-TIME IMPURITY CONFINEMENT \\ AS A PRECURSOR TO DISRUP'TIONS \\ IN OHMICALLY HEATED TOKAMAKS
}

Ralph C. Isler

Fusion Energy Division $\quad$ DE88 006183

ORNL

and

William L. Rowan

Fusion Research Center

University of Texas at Austin

Presented at the IAEA Technical Committee Meeting on Density Limits and Disruptions Abingdon, England - 26 - 28 January, 1988

Work sponsored by the Office of Fusion Energy, L. S. Department of Energy, under contract No. DE-AC05-84OR21400 with Martin Marietta Energy Systems Inc. 
- It has been observed in several tokamaks that the confinement of test impurities increases dramatically when operating near density limits. The characteristics of the working gas transport coefficients also change character under these conditions.

- These changes appear to be caused by a supression of the anomalous transport mechanisms. What role do they play in initiating disruptions? 


\section{TOPICS}

- TEST IMPURITY CONFINEMENT NEAR DENSITY LIMITS AND INTRINSIC IMPURITY ACCUMULATION.

- SOFT AND HARD DISRUPTIONS.

- SAWTOOTHING AND LOW MHD MODE BEHAVIOR.

- COMPARISON OF HYDROGEN AND DEUTERIUM DISCHARGES.

- UNIVERSALITY OF OBSERVATIONS. 


\section{Two Types of Disruptions Are Observed}

* Soft or partial disruptions. These are preceeded by impurity accumulation, central cooling, and little or no increase in MHD activity. $I_{p}$ does not go to zero, but confinement is poor after the disruption.

* Hard or complete disruptions. Impurity accumulation may or may not be observed. MHD activity increases before the disruption, then $I_{p}$ drops rapidly to zero.

In both cases observed in the TEXT tokamak, a transition to long-time confinement of test impurities preceeded the disruption 


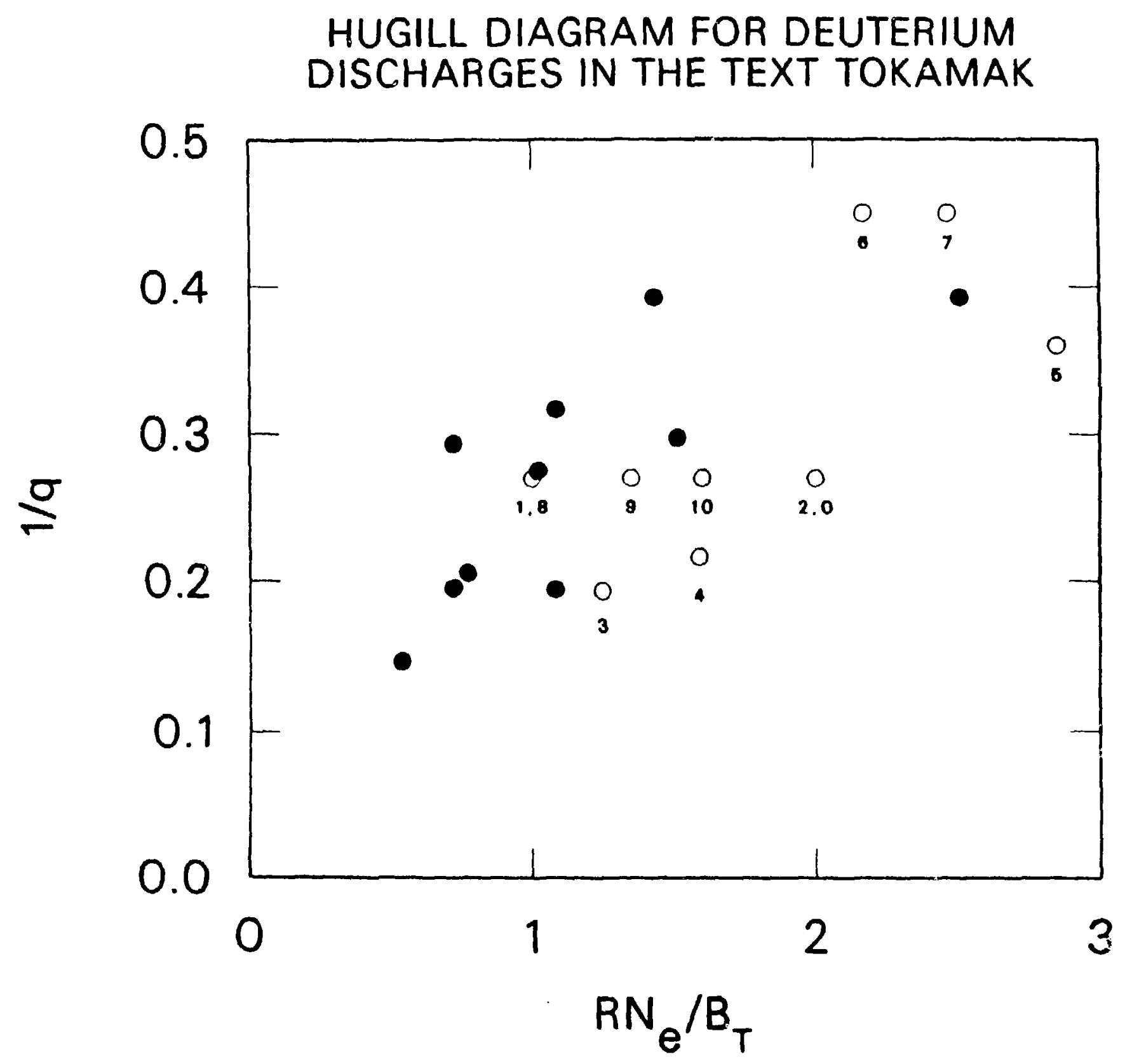



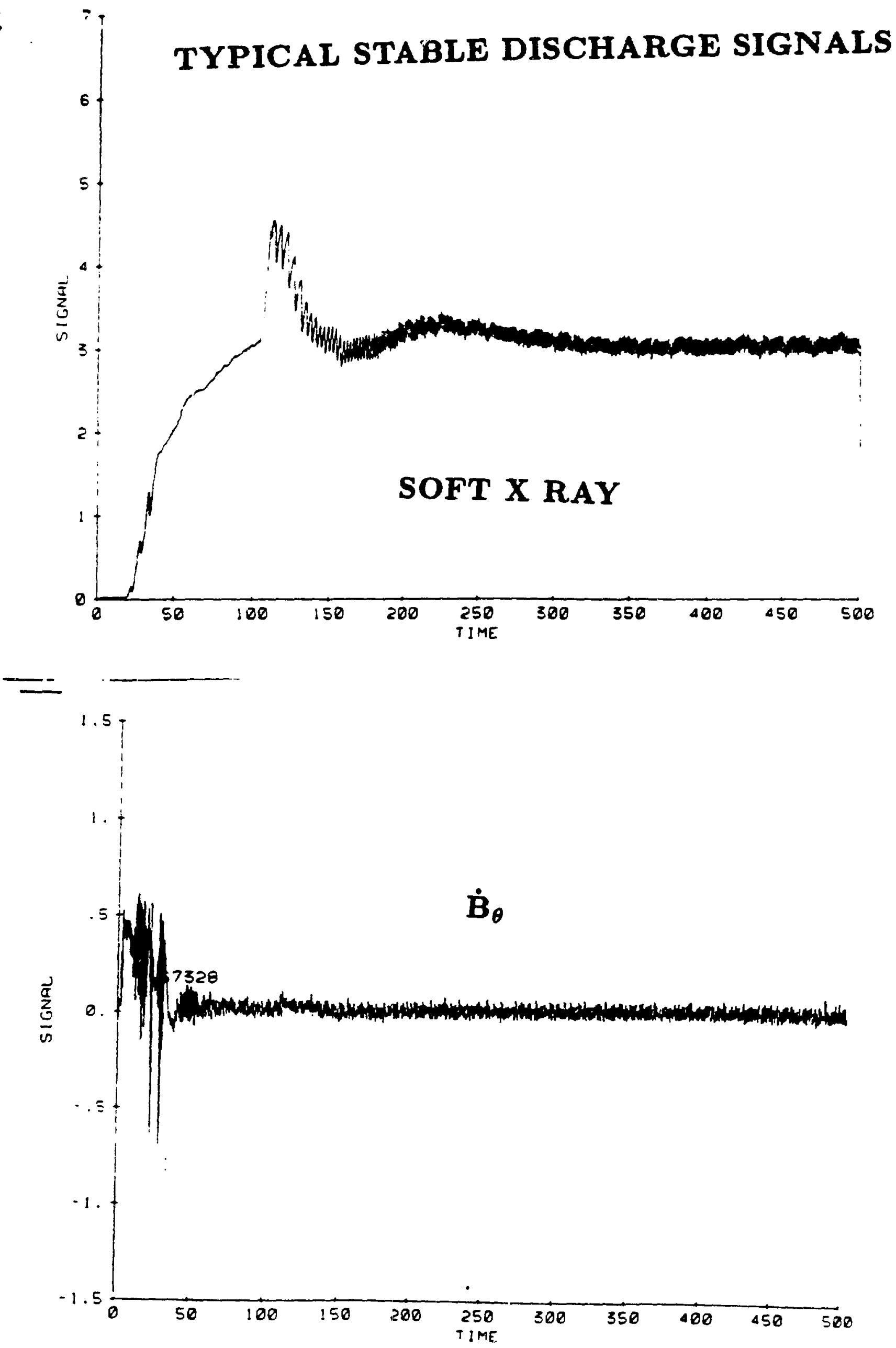

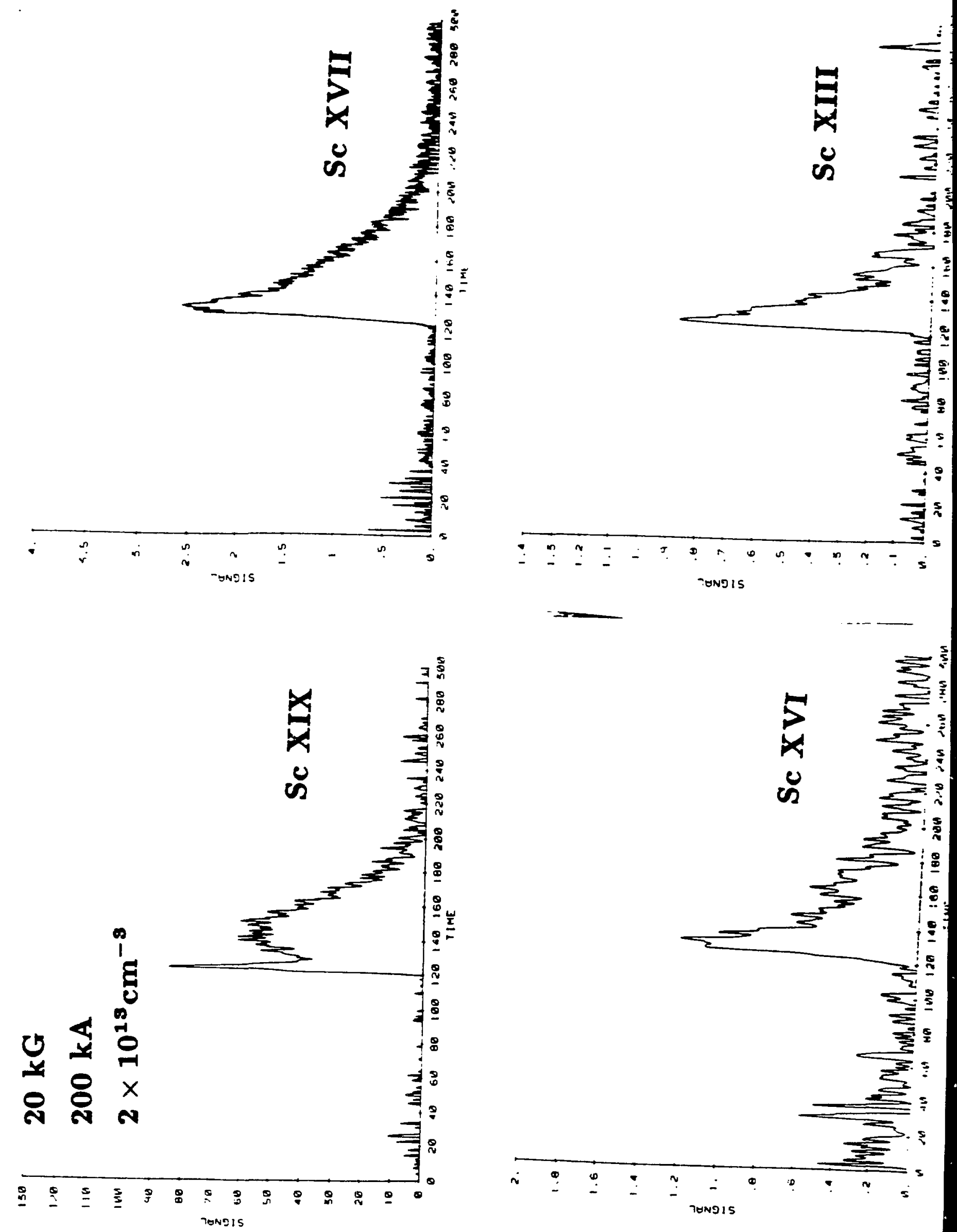


\section{Alcator Impurity Scaling}

$$
\tau_{z} \propto \frac{m_{b} I_{p}}{B_{T}} \frac{Z_{e} f f}{Z_{b}}
$$

\section{TEXT Results for Disruptive Discharges}

$$
\tau_{z} \longrightarrow \frac{f_{1}\left(n_{e}\right)}{f_{2}\left(B_{T}\right) f_{3}\left(I_{p}\right)}
$$

1. $B_{T}$ DEPENDENCE AGREES

2. $I_{p}$ DEPENDENCE DOES NOT AGREE

3. $N_{e}\left(Z_{e} f f\right)$ DEPENDENCE DOES NOT AGREE 

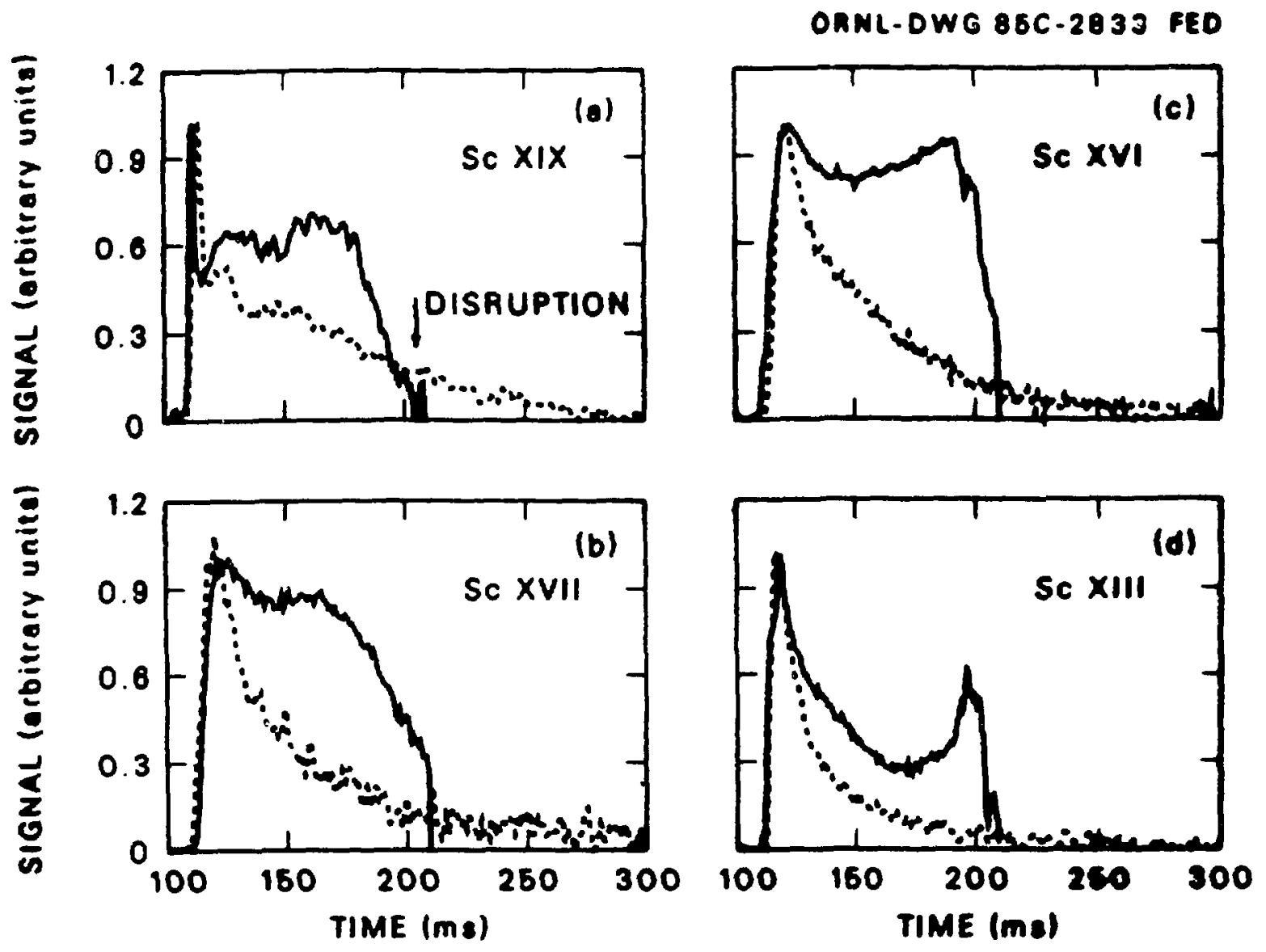

$$
\begin{aligned}
\longrightarrow \frac{\bar{n}_{C}}{B_{T} I_{P}} & =1.4 \times 10^{4} \mathrm{~cm}^{-3} \mathrm{G}^{-1} \mathrm{~A}^{-1} \\
& =0.62 \times 10^{4}
\end{aligned}
$$




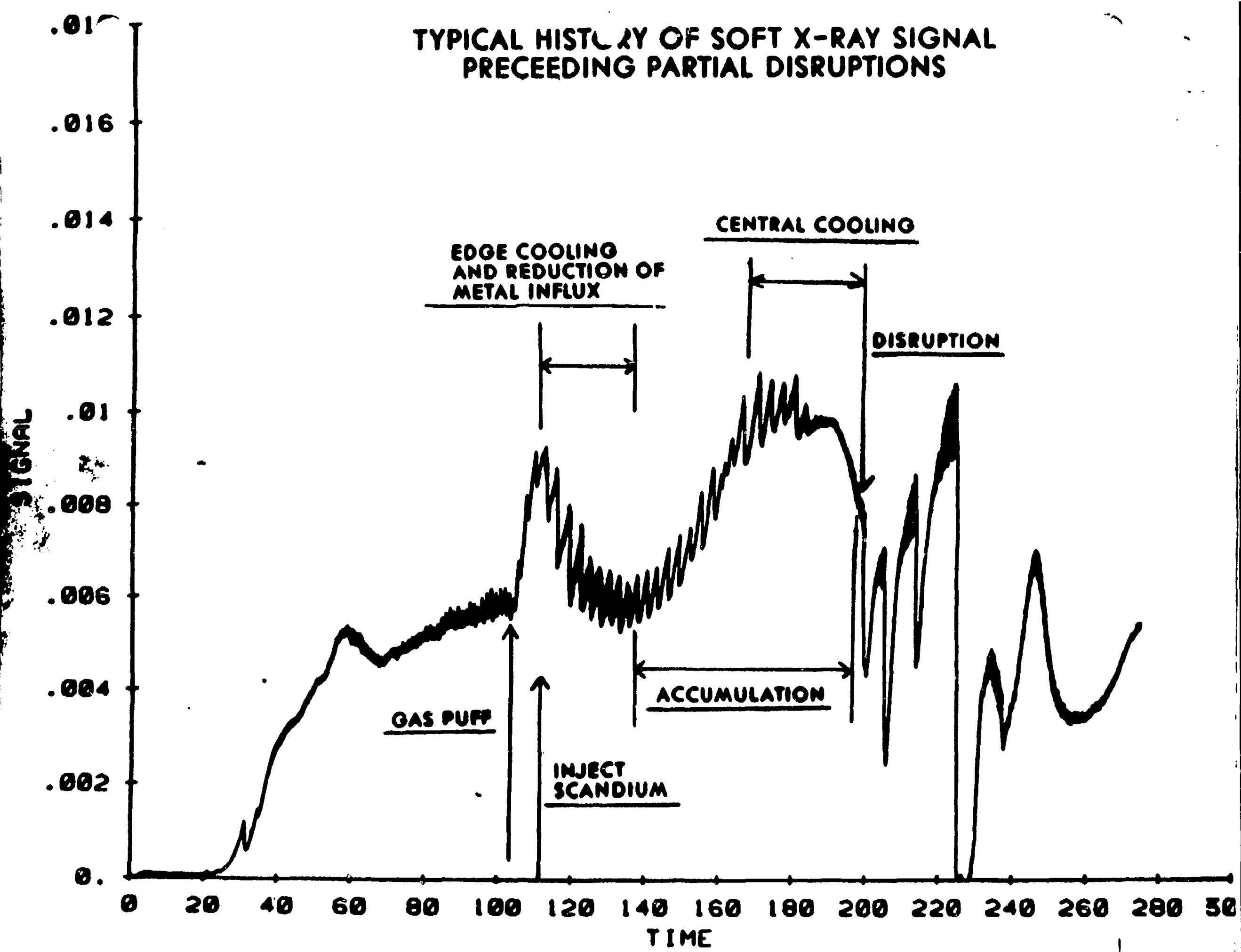



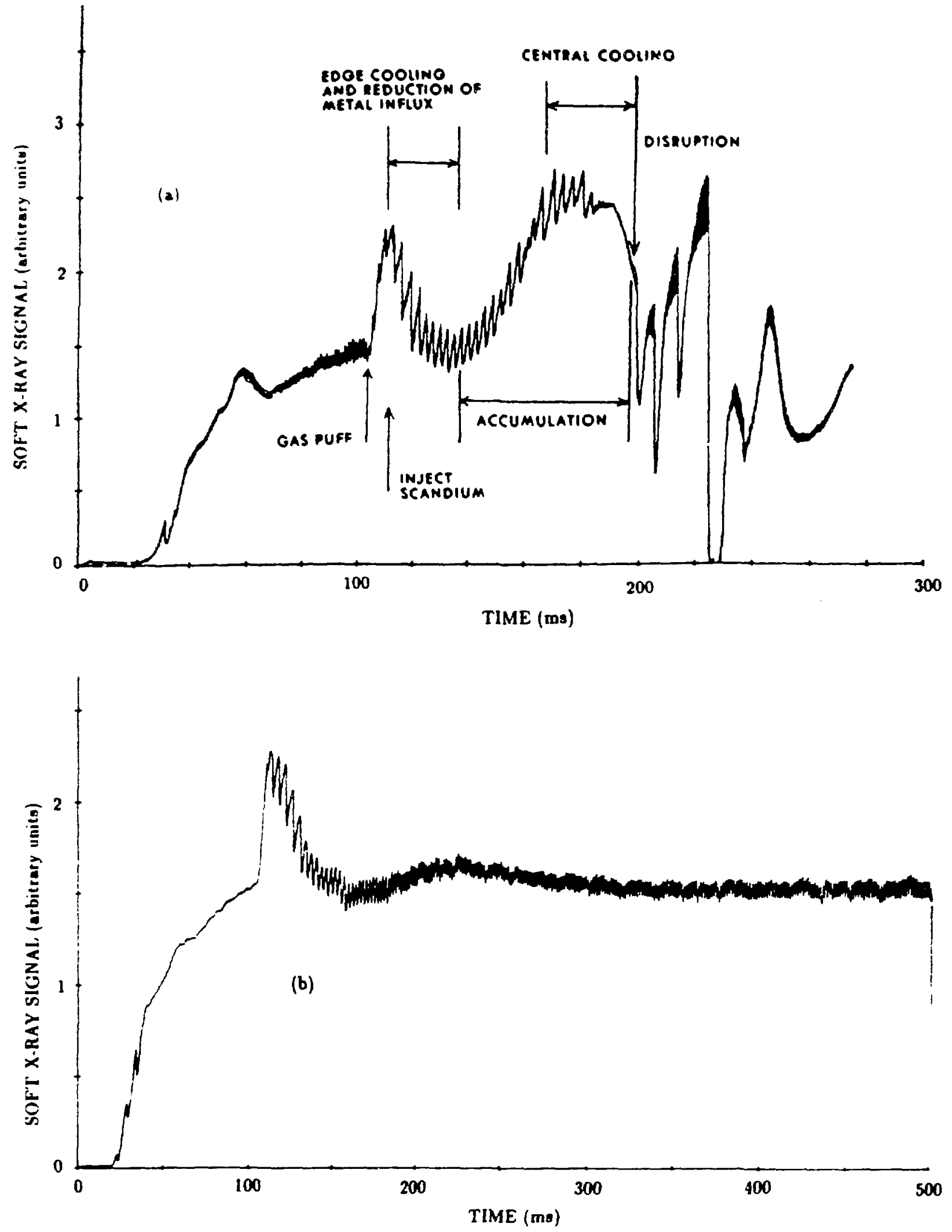


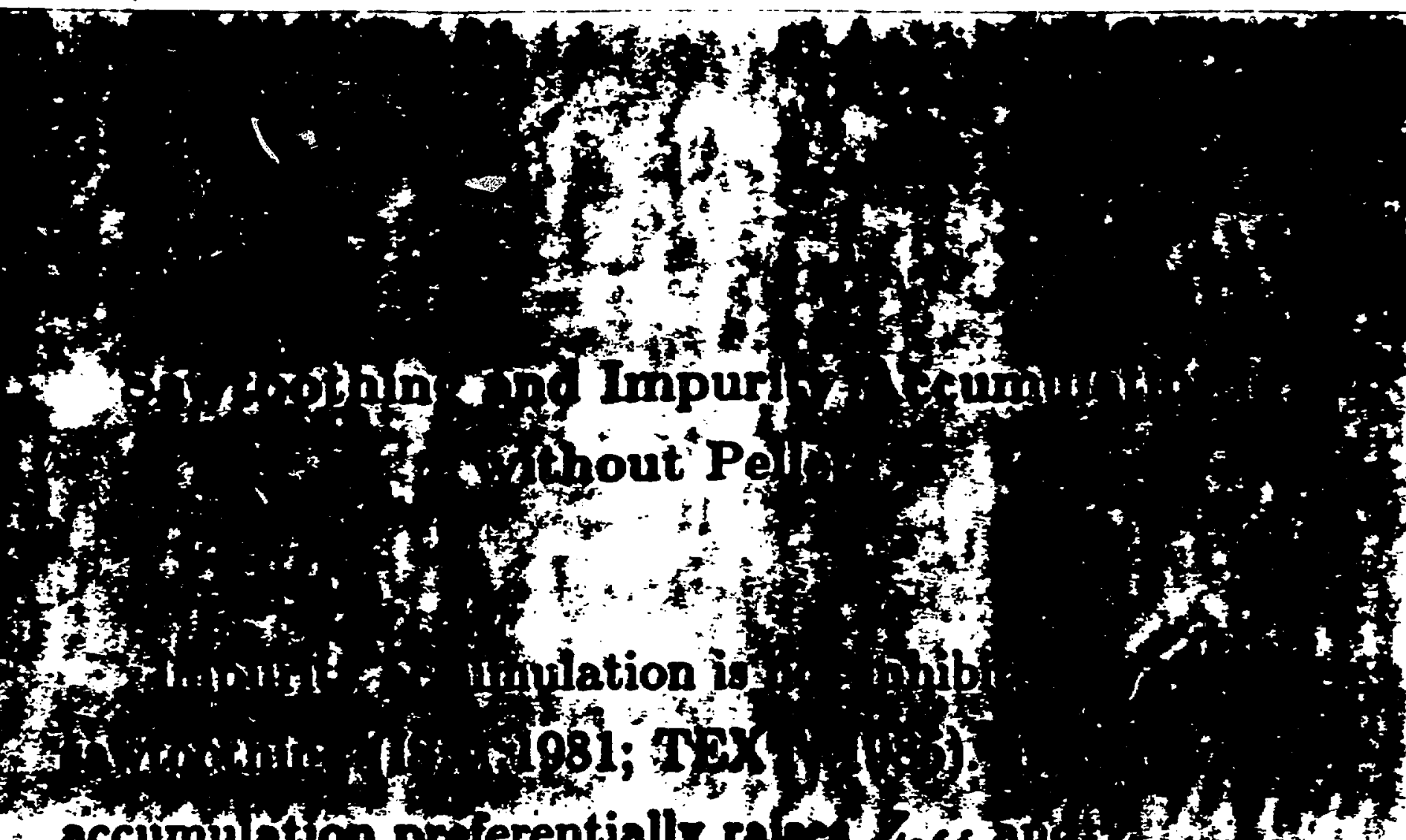

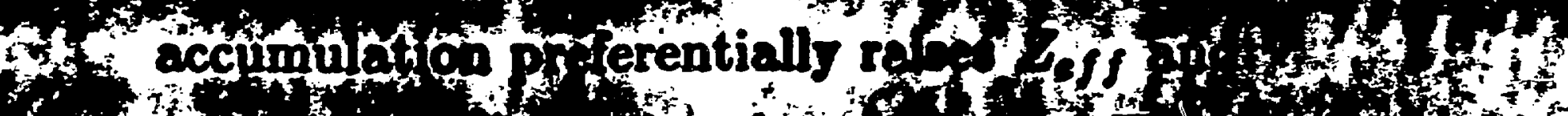

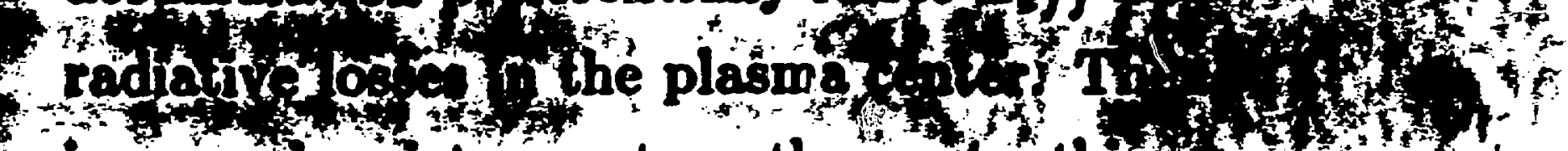
$F$ increased resistance stops the sawtoothing t.

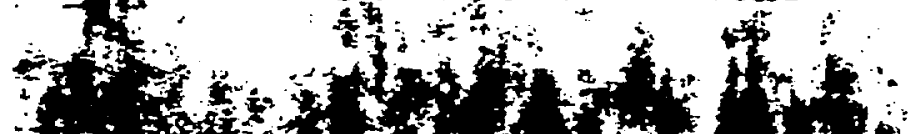

8

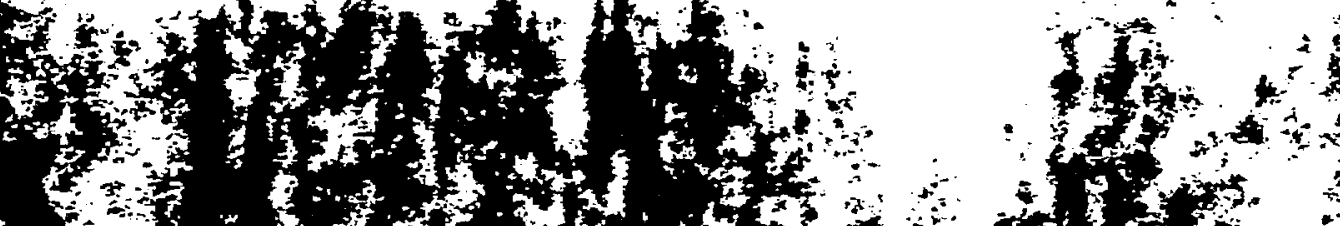

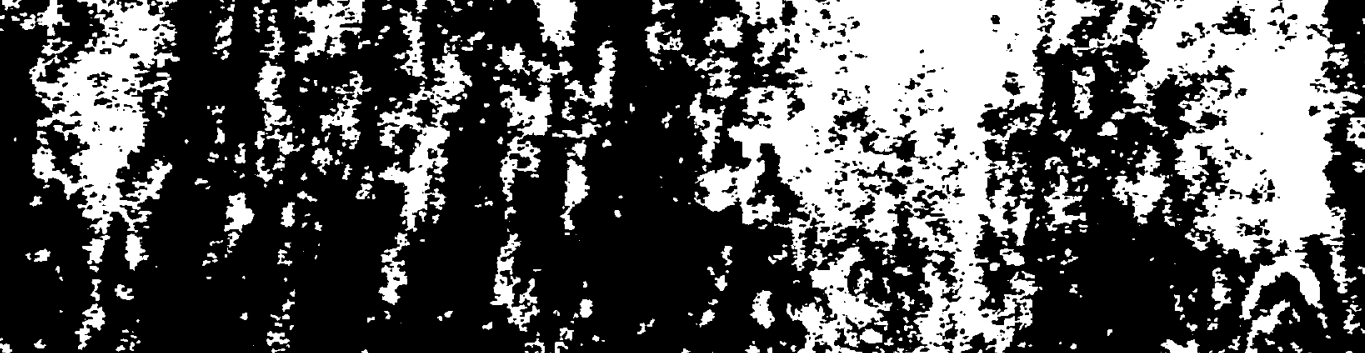
thom $\rightarrow$ ontos.

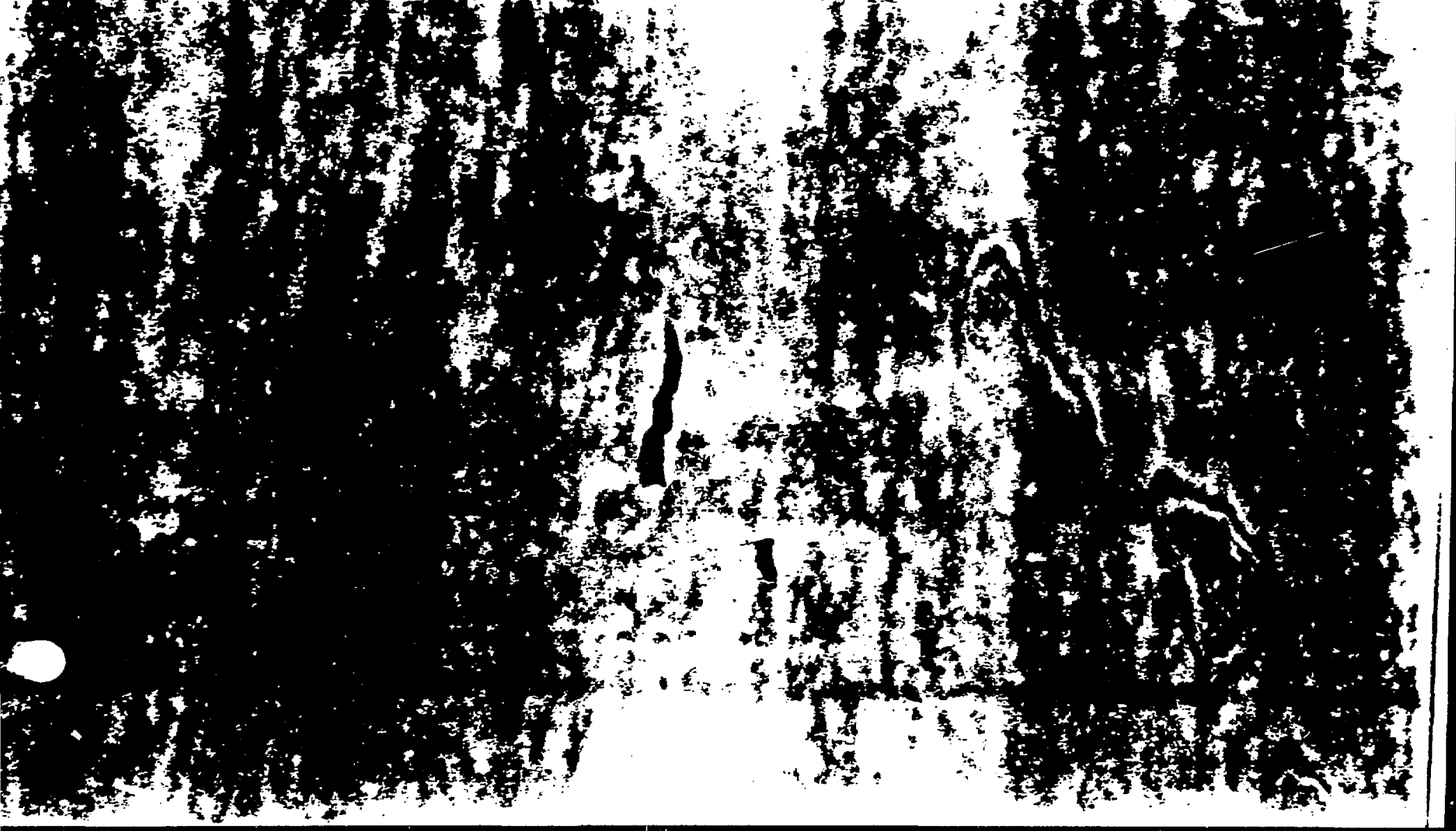




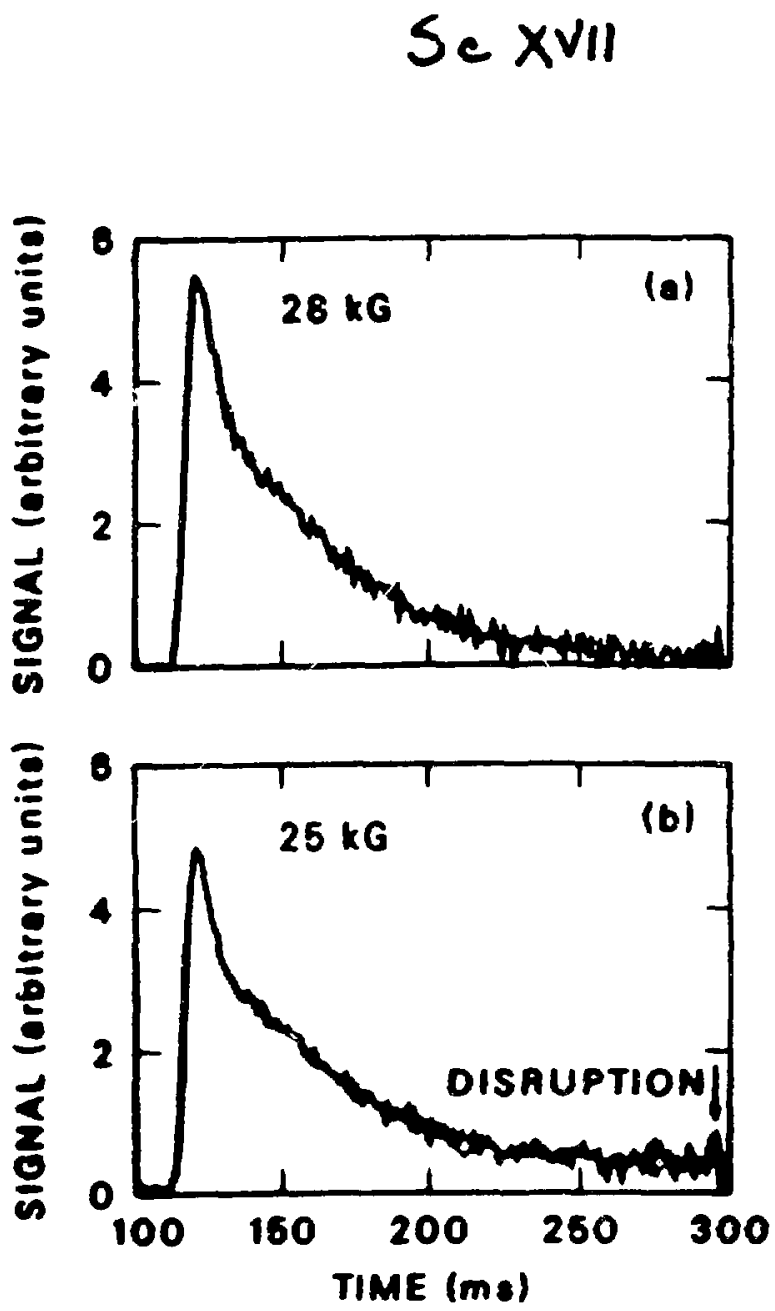

TEXT

ONNL.DWG OBC.2838 FED
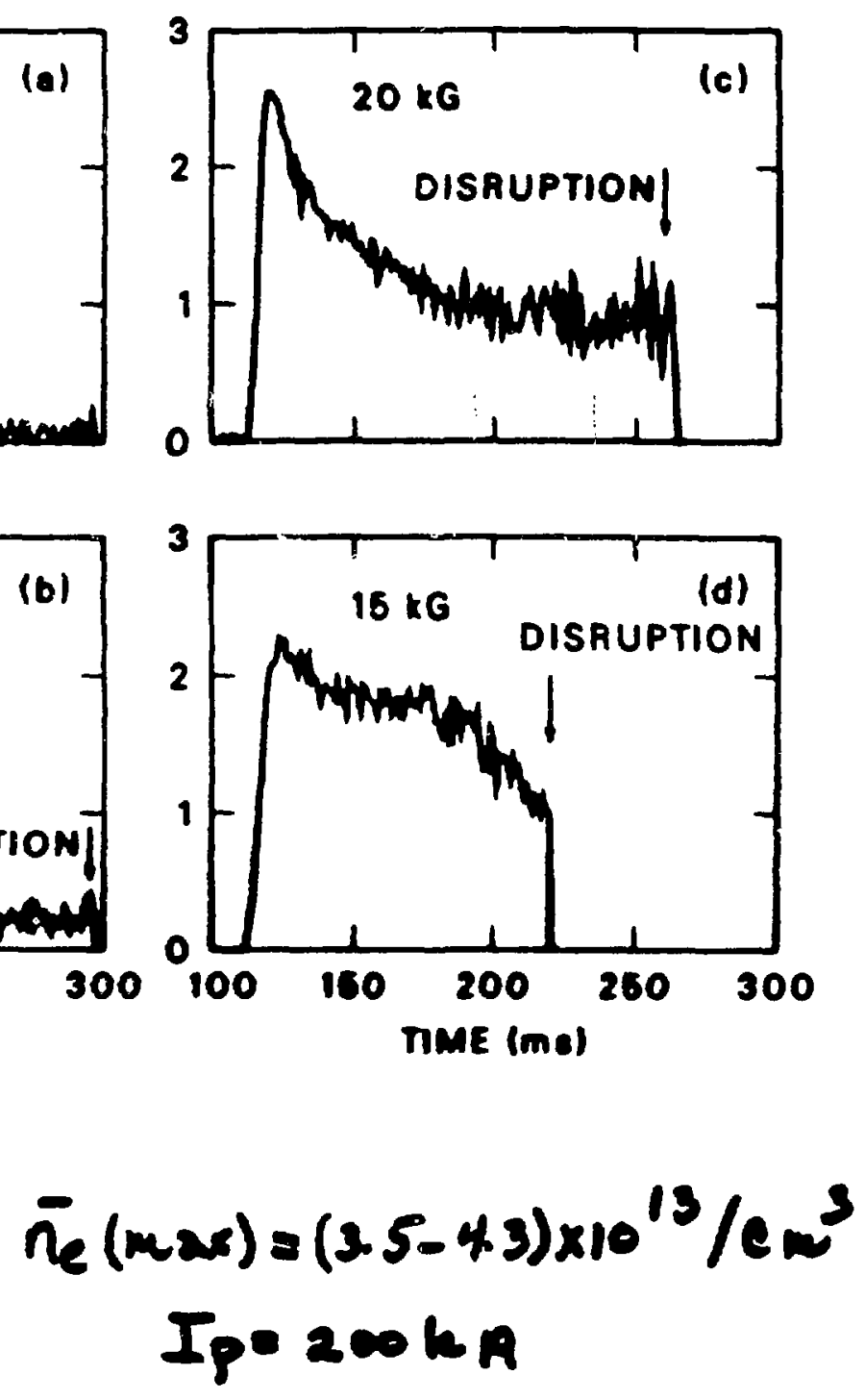

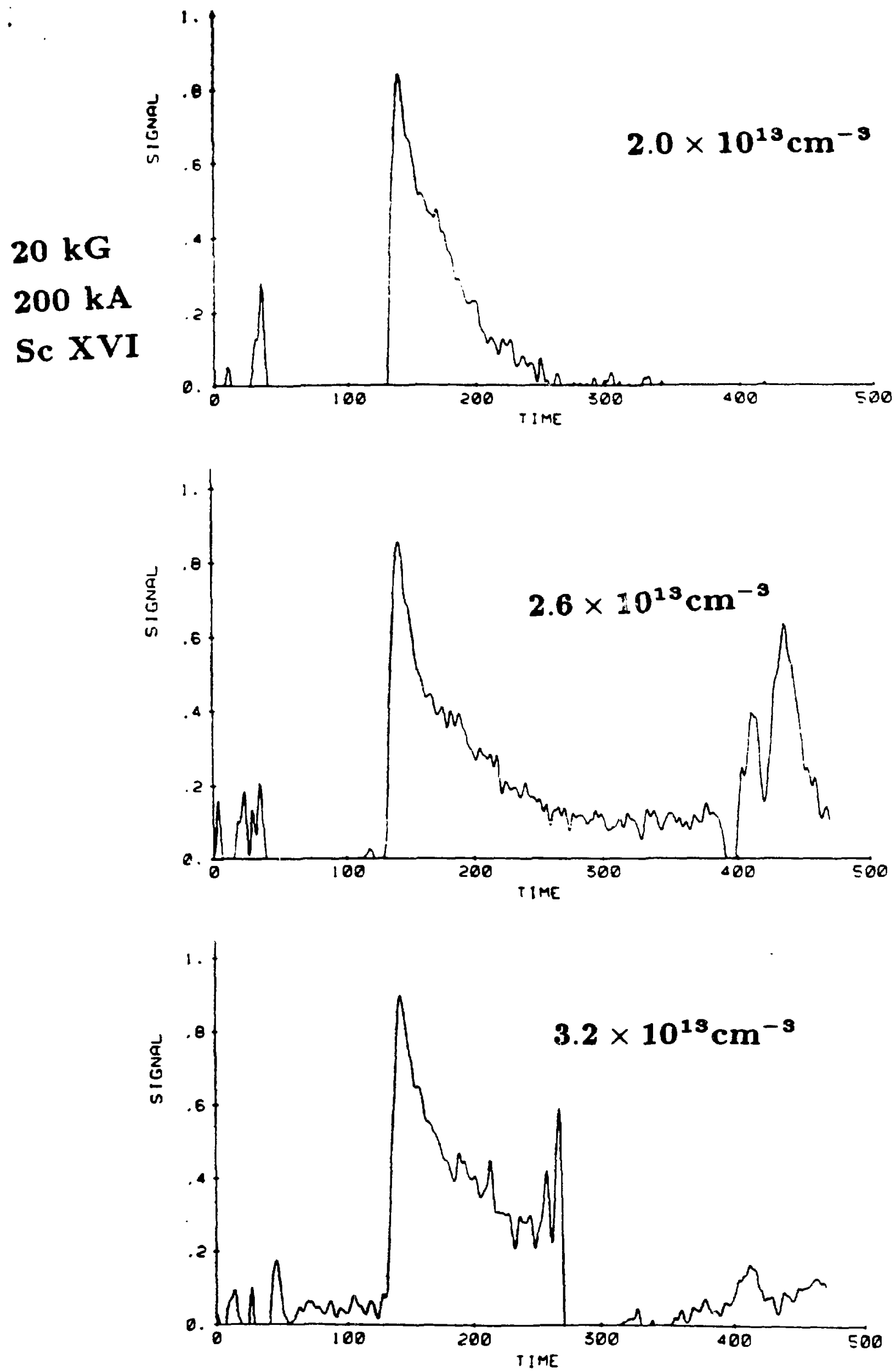

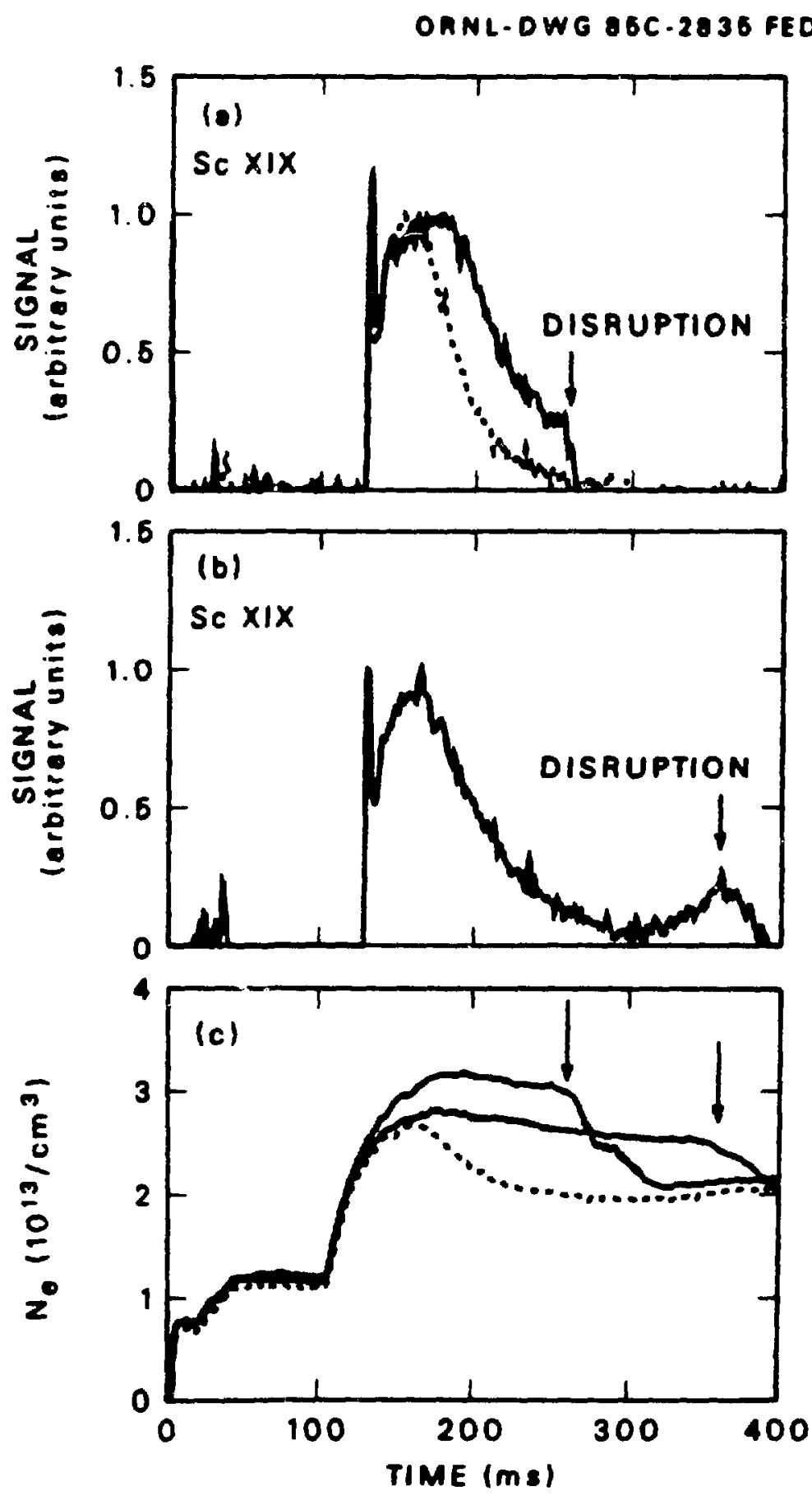

- Isler et al., Fig. 5 
SIGNAL

larbitrary units)
SIGNAL

(arbitrary units)
SIGNAL

arbitrary units)

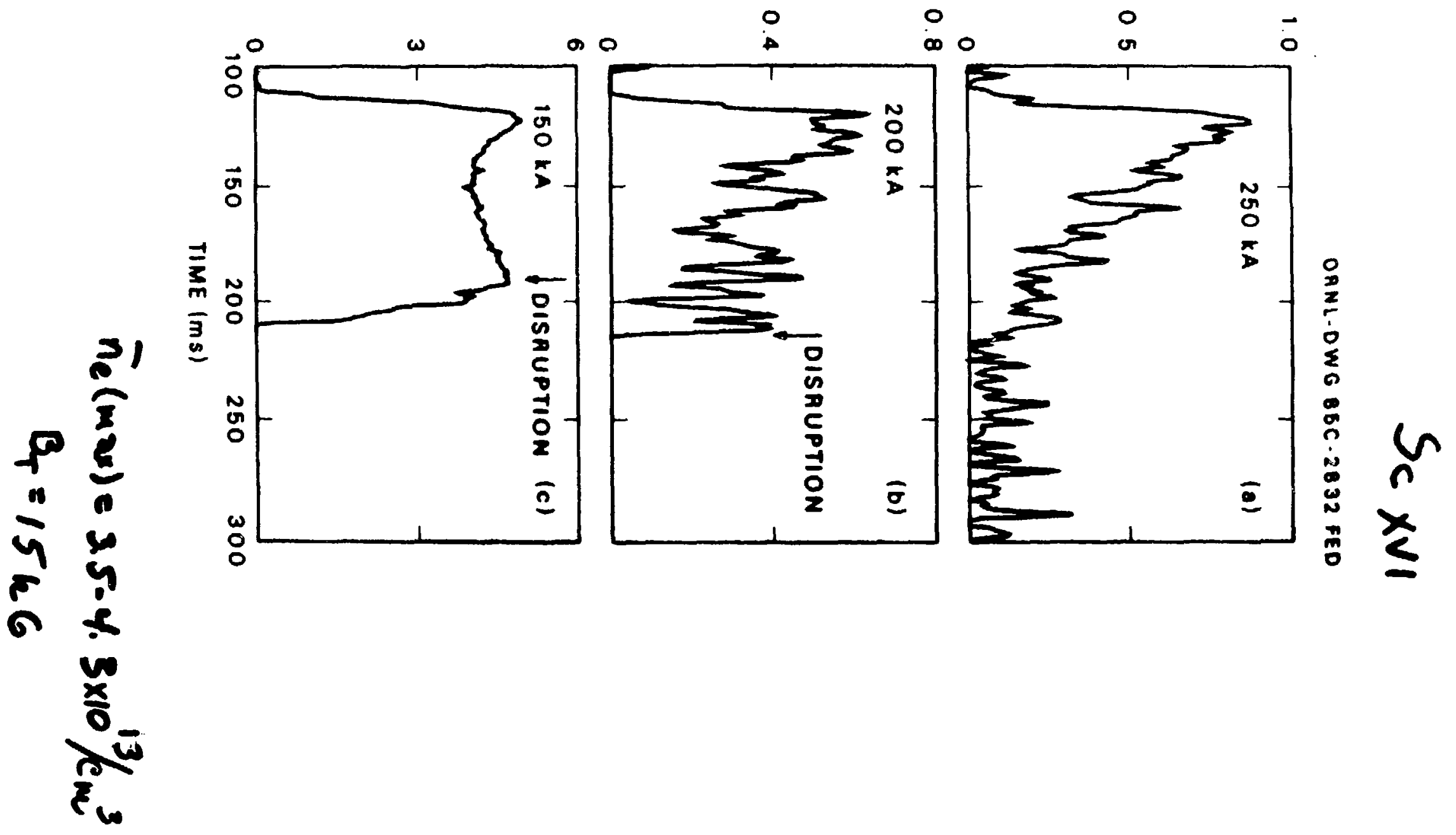



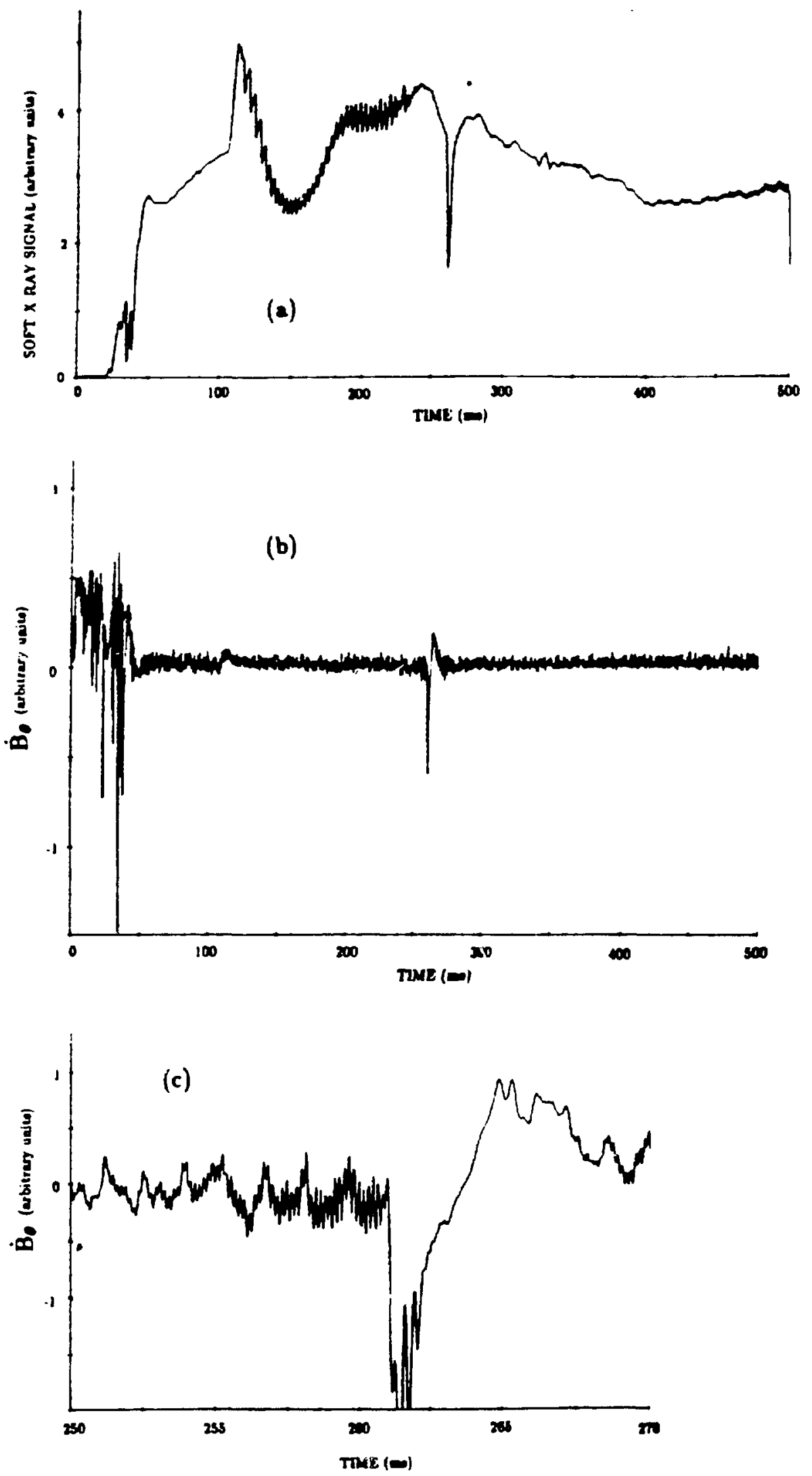


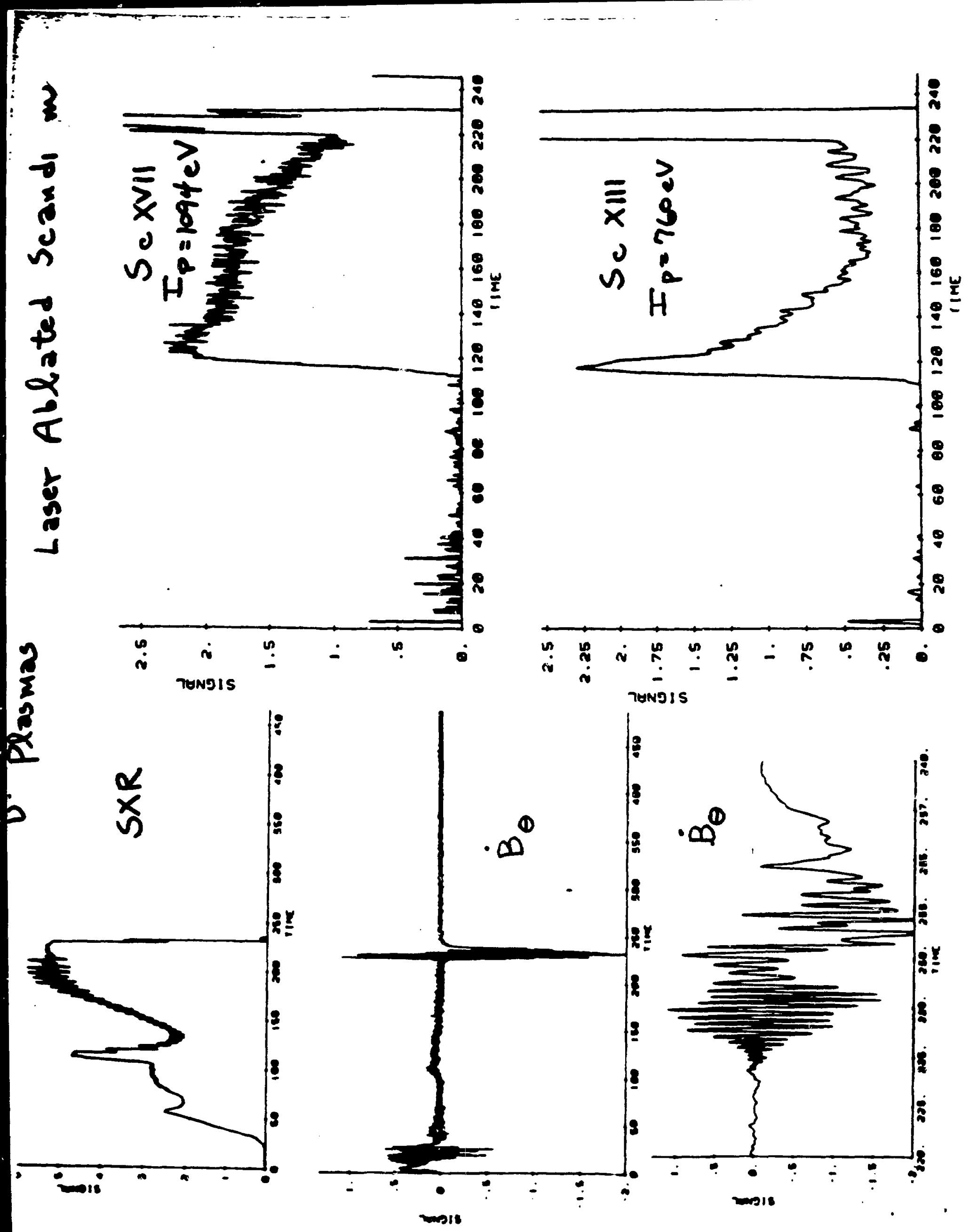



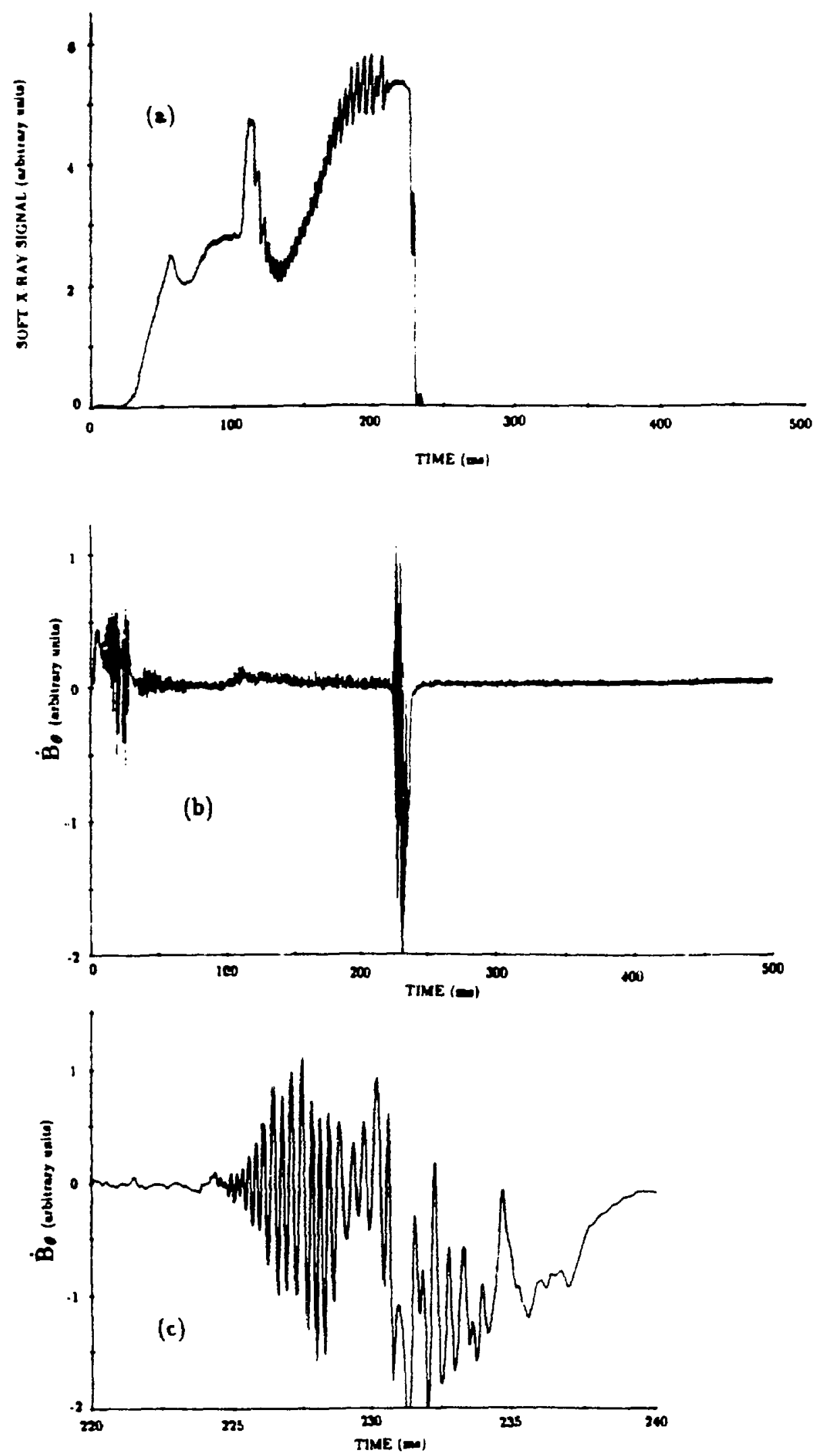

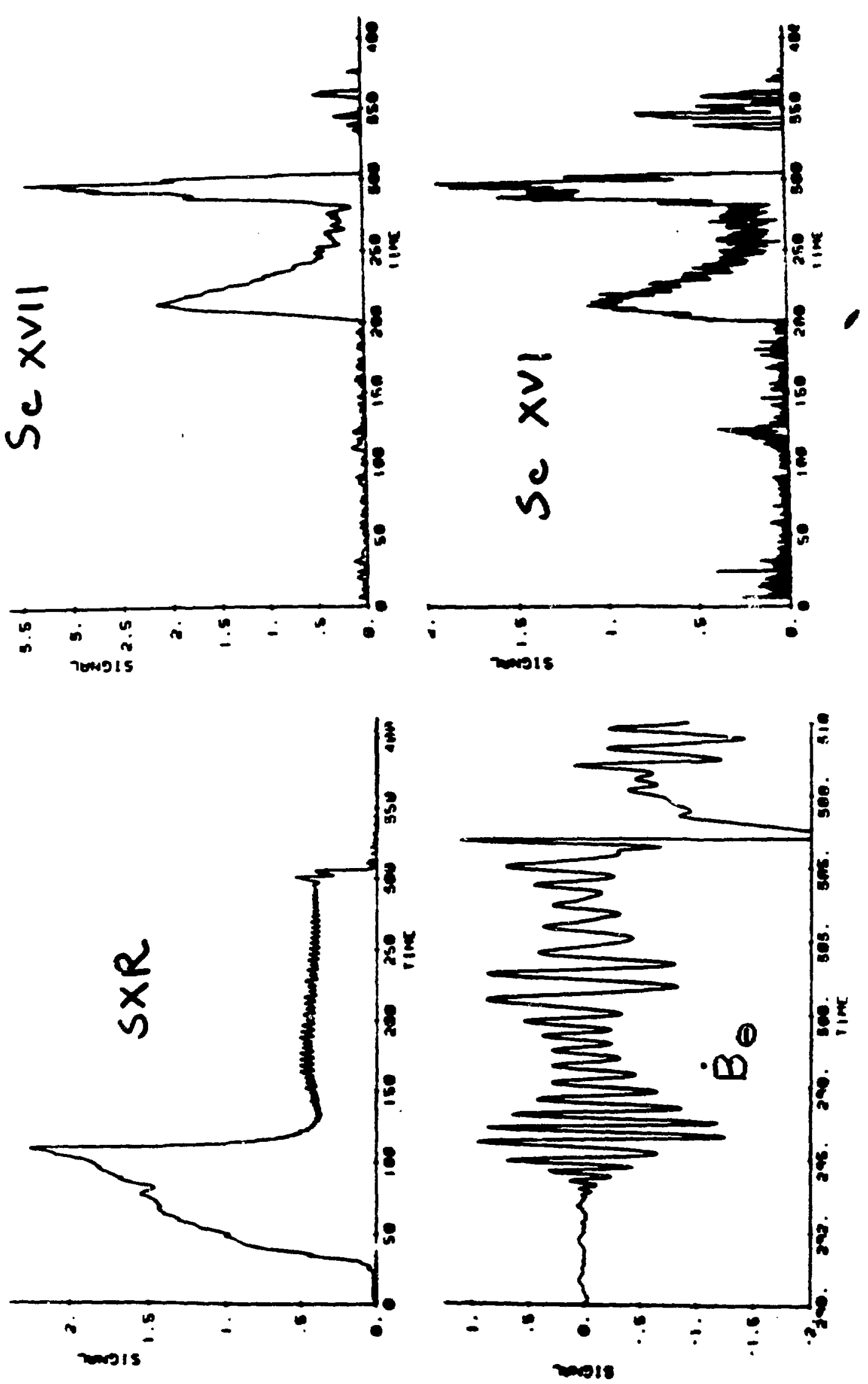


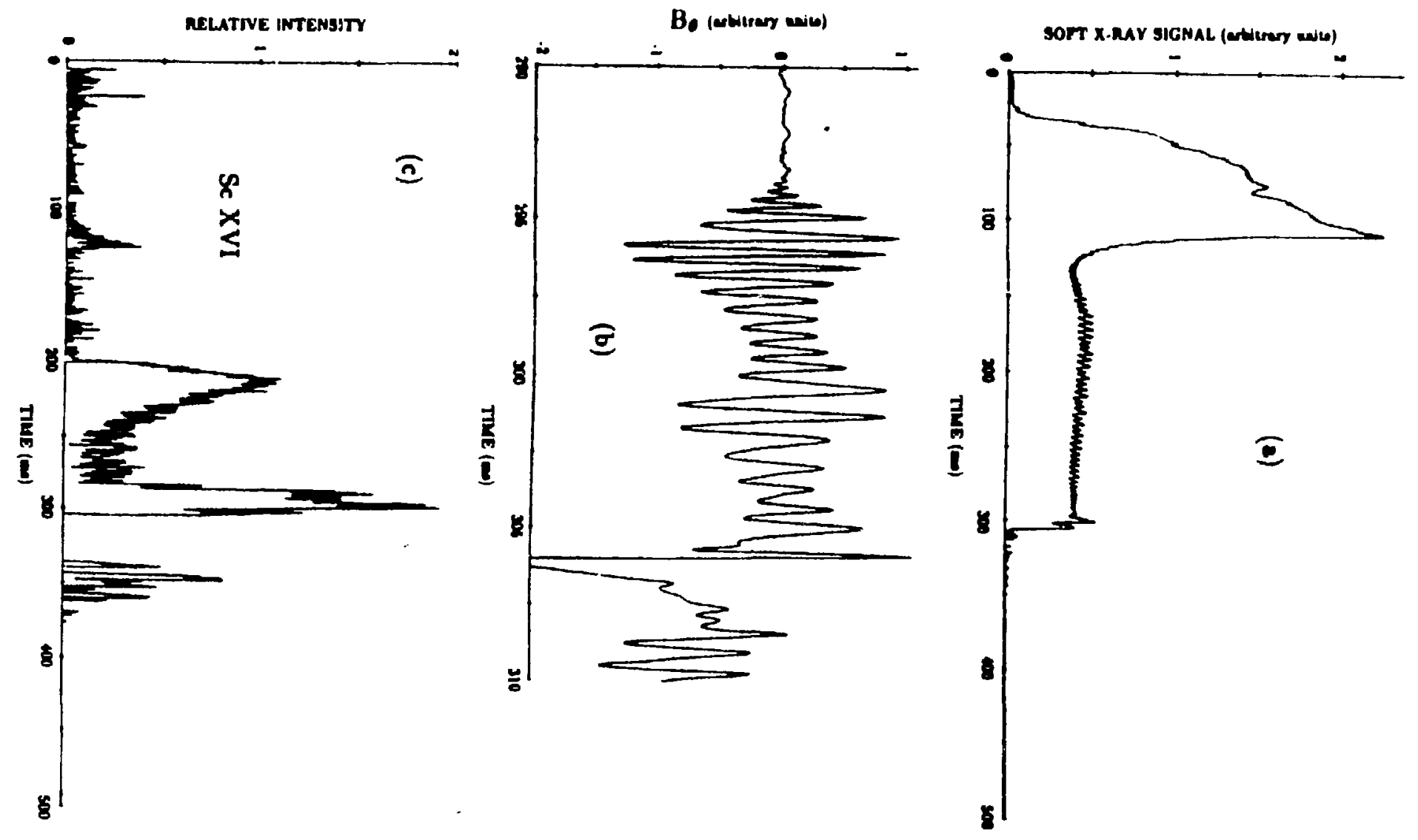



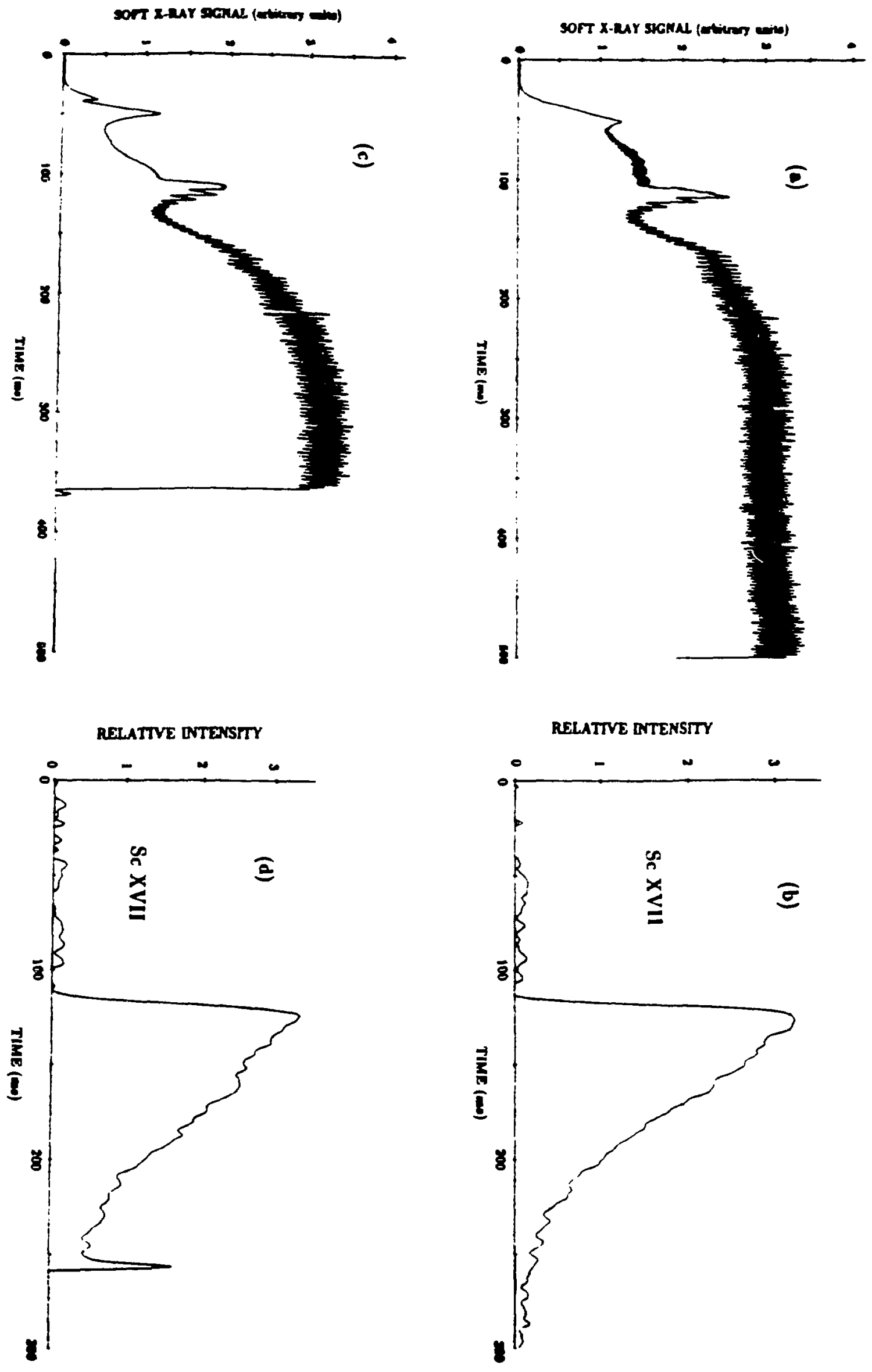


\section{RESULTS OF TRANSPORT STUDIES OF HYDROGEN AND DEUTERIUM IN THE TEXT TOKAMAK \\ K. Gentle, B. Richards, F. Waelbroeck}

- WORKING GAS TRANSPORT CAN BE MODELED BY CONSTANT D AND V EXCEPT NEAR DENSITY LIMITS. D AND V SCALE AS $1 /$ nq.

- D FOR DEUTERIUM IS SYSTEMATICALLY LOWER THAN FOR HYDROGEN.

- NEAR THE DENSITY LIMI' ${ }^{2}$ D AND V ARE NOT UNIFORM:

* IN THE CORE, D IS SMALLER THAN EXPECTED FROM THE $1 /$ nq SCALING, $\mathrm{V} \approx 0$,

* in the edge D and V are both higher than EXPECTED FROM THE 1/nq SCALING. 
SOFT X-RAY (PIN) SIGNALS REFLECT

THE DIFFERENCES OF IMPURITY ACCUMULATION BETWEEN DEUTERIUM AND HYDROGEN
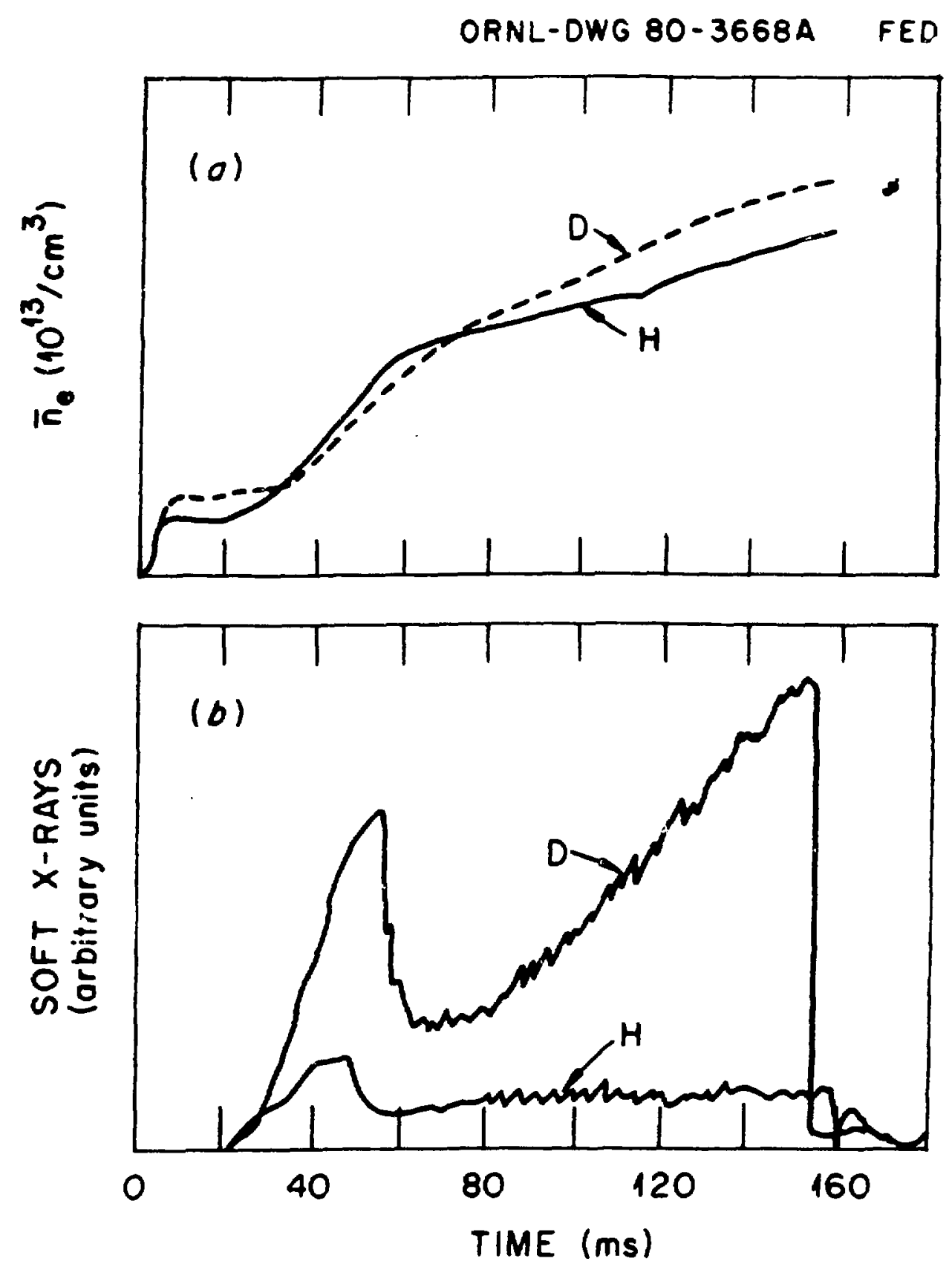

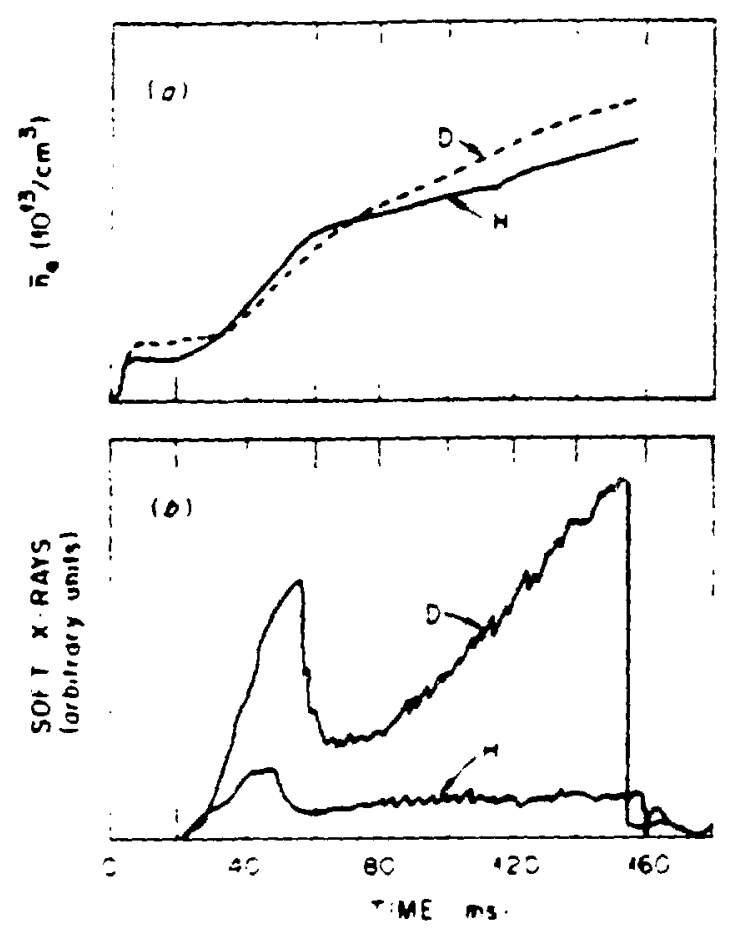

FG. 1. The line-averaged electron concentrations and the soft-x-ray signals during Chmically beated deuterium $(D)$ and hydrogen $(H)$ discharges.

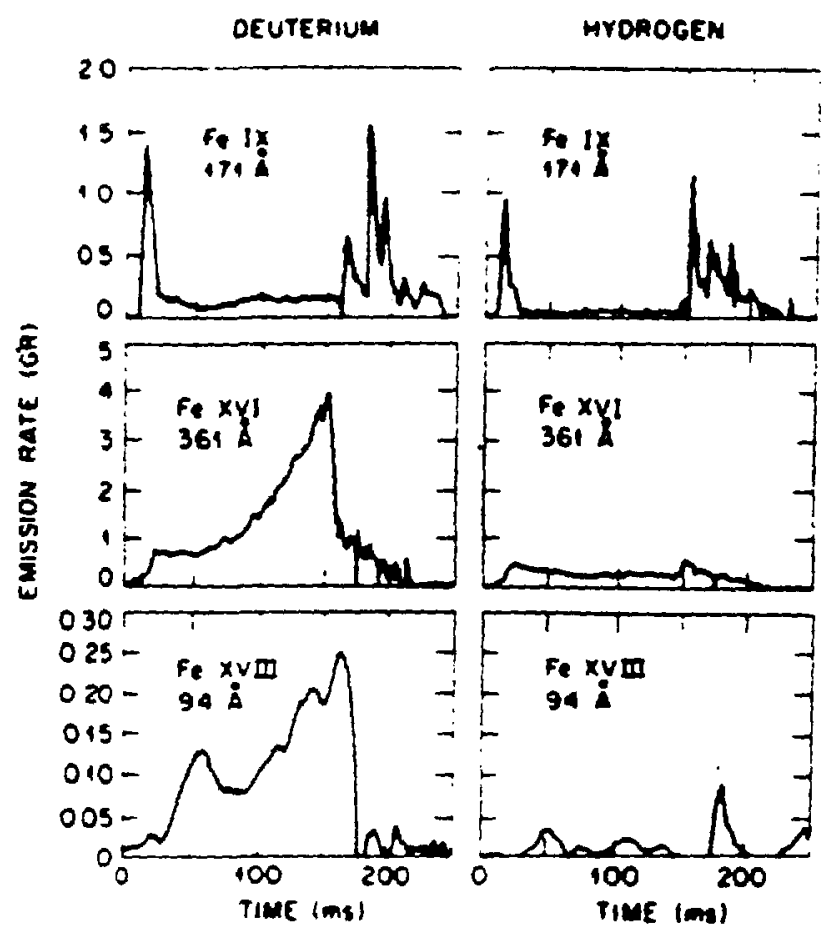

FIG. 2. Comperisons of the emisstos rates 11 etourayleigh $=10^{15}$ photons $/ \mathrm{cm}^{2}$ al trom several tron lises duriag Ohmicelly heated deuterlum and bydrogen diecharges. 


\section{SOFT X-RAY SIGNALS INDICATE THAT THE IMPURITY CONTENT} INCREASES DURING DEUTERIUM DISCHARGES BUT SOON REACHES AN ALMOST STEADY STATE IN HYDROGEN DISCHARGES.

$$
\text { ORNL-DWG 81-3407 FED }
$$

HYDROGEN
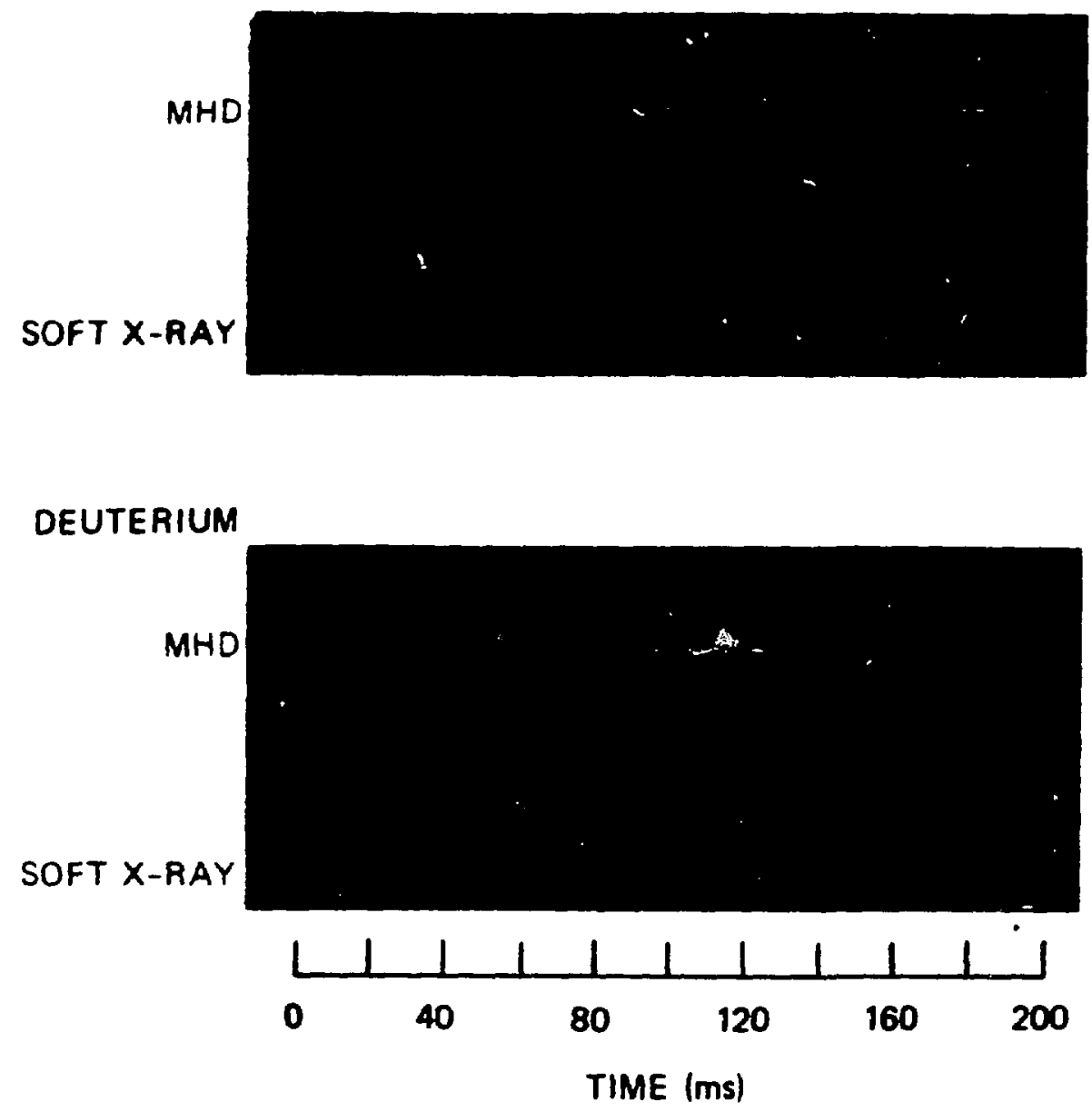


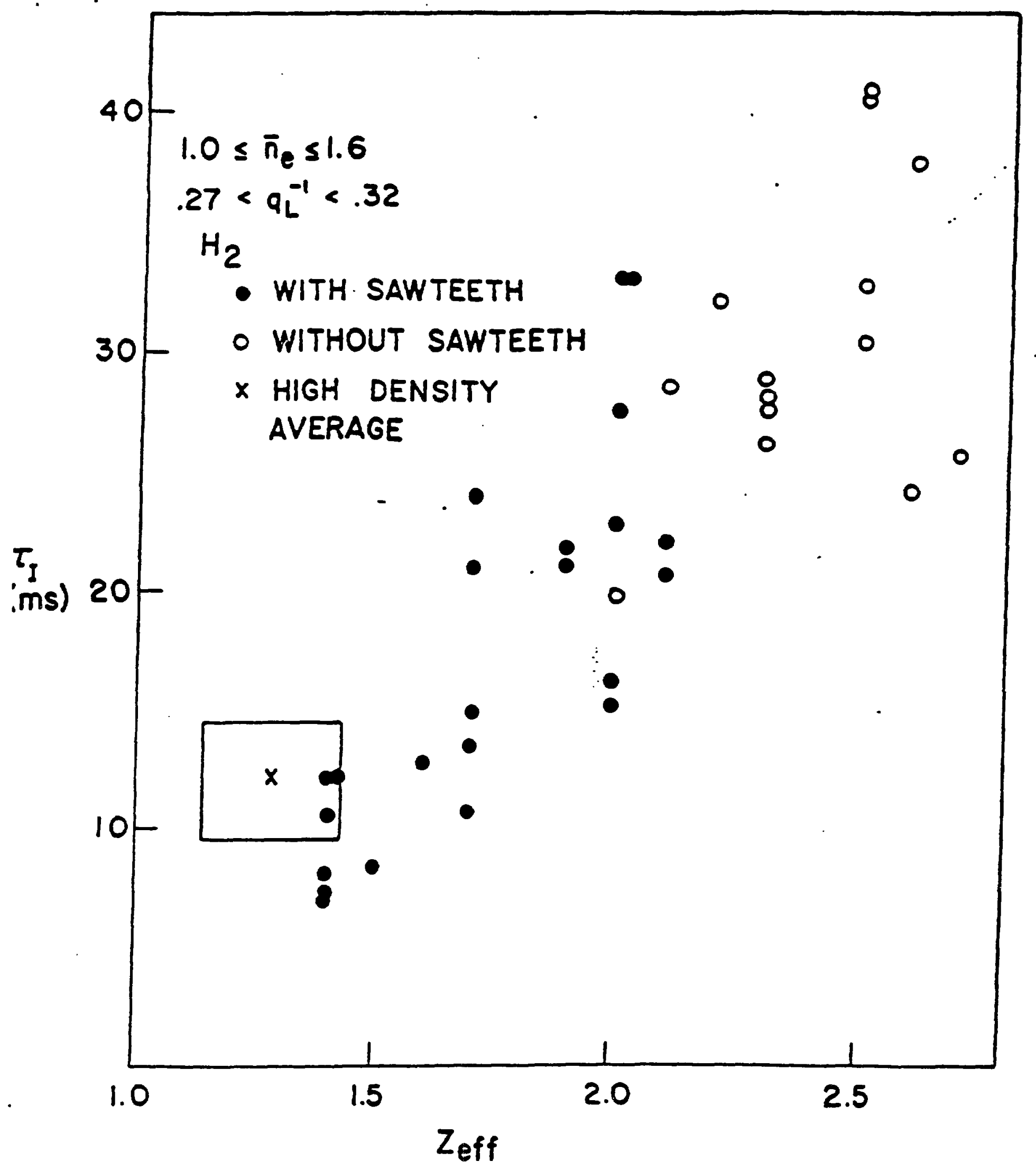

FIGURE 10 
NON-GETTERED

$$
Z_{\text {. } f s}=2.8
$$
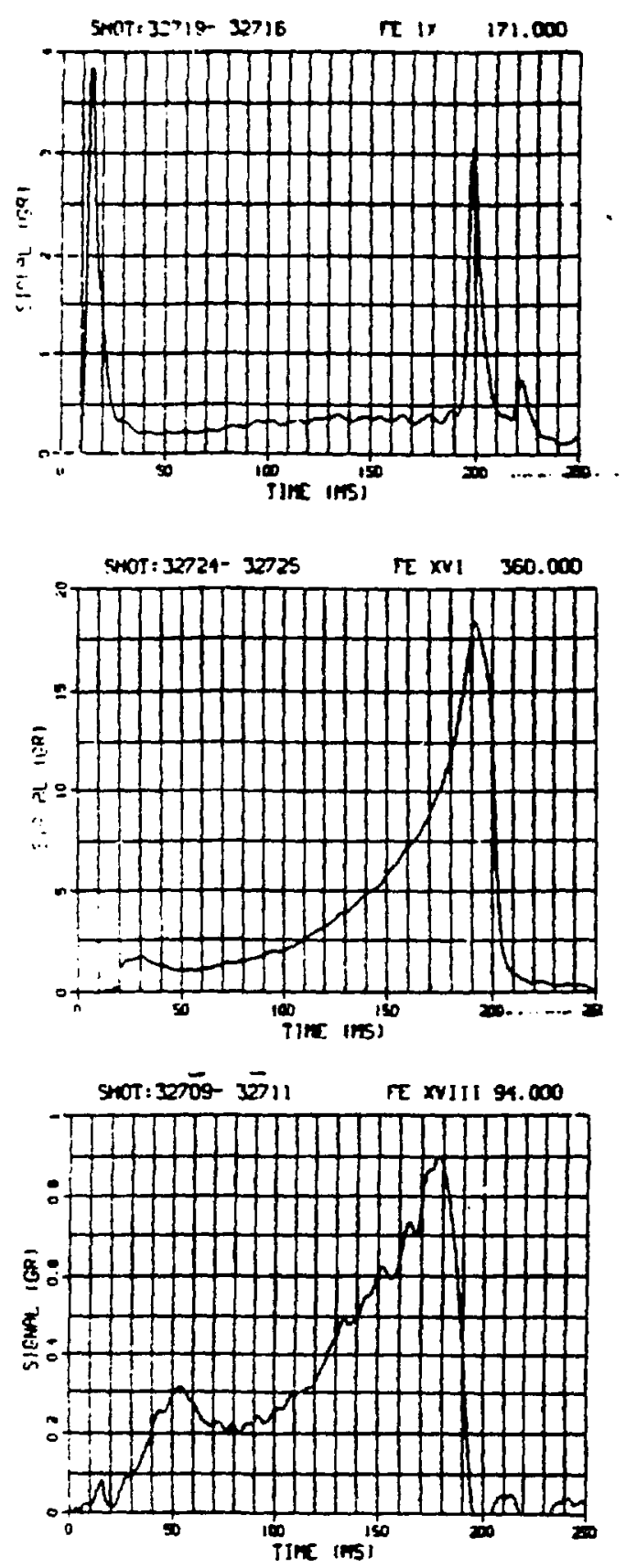

GETTERED

$Z_{e f f}=1.5$
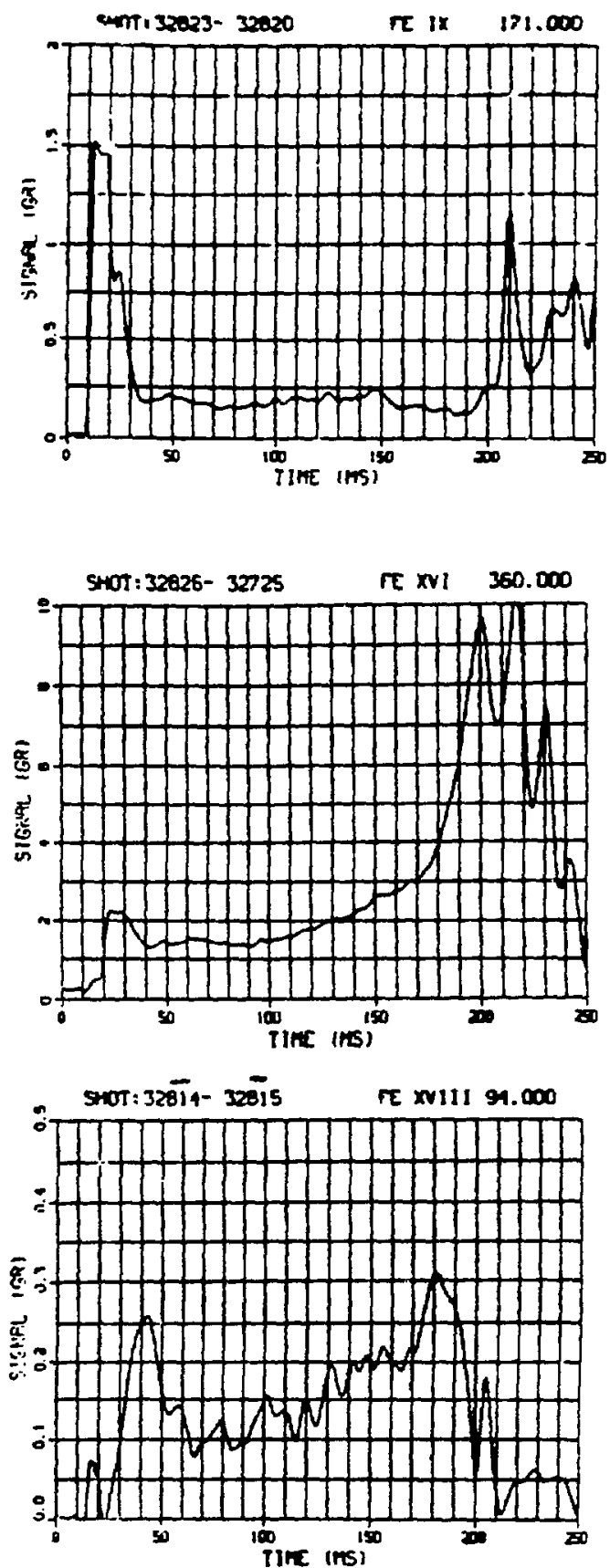


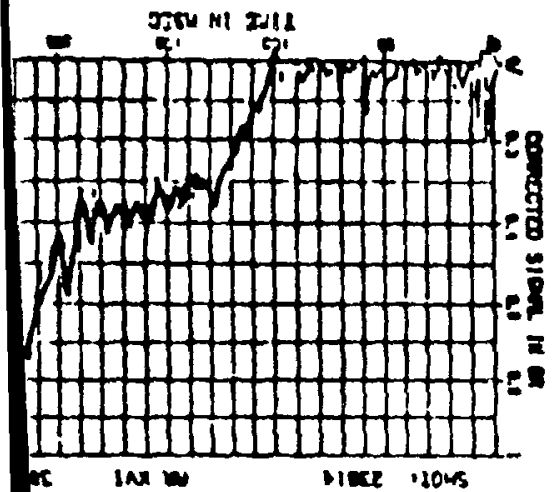

$x_{\text {ind }}$ bece rous
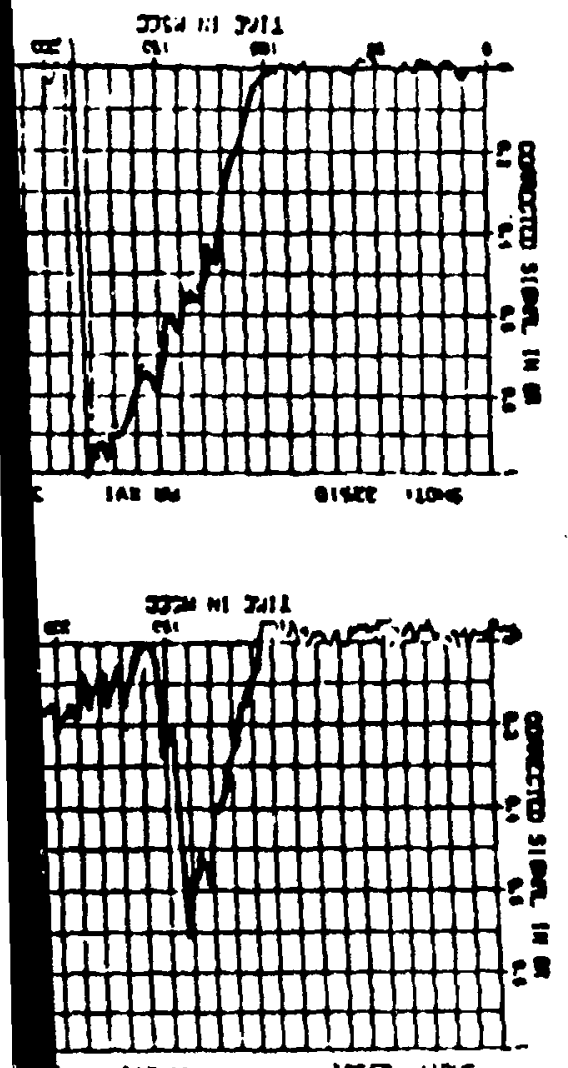
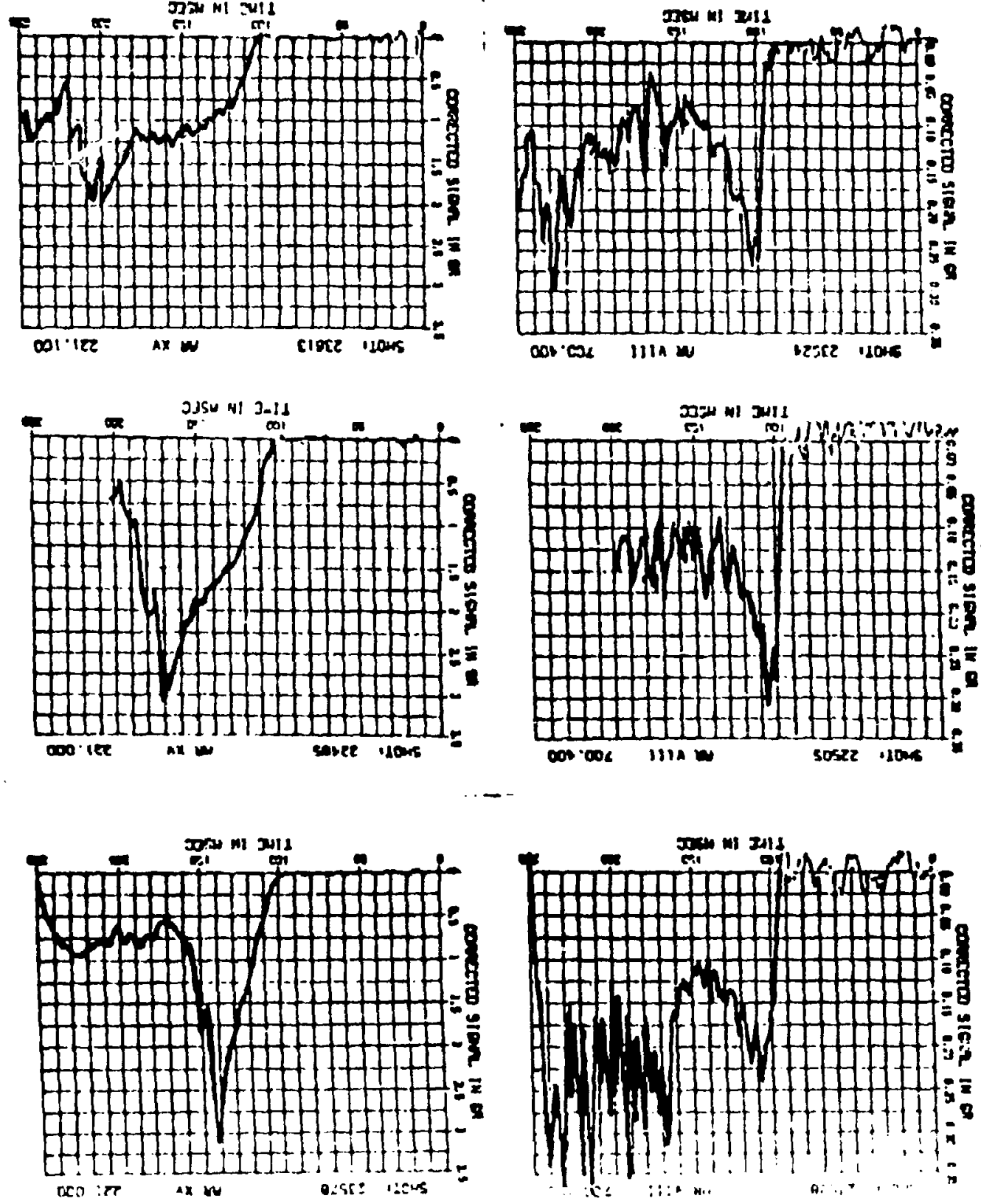
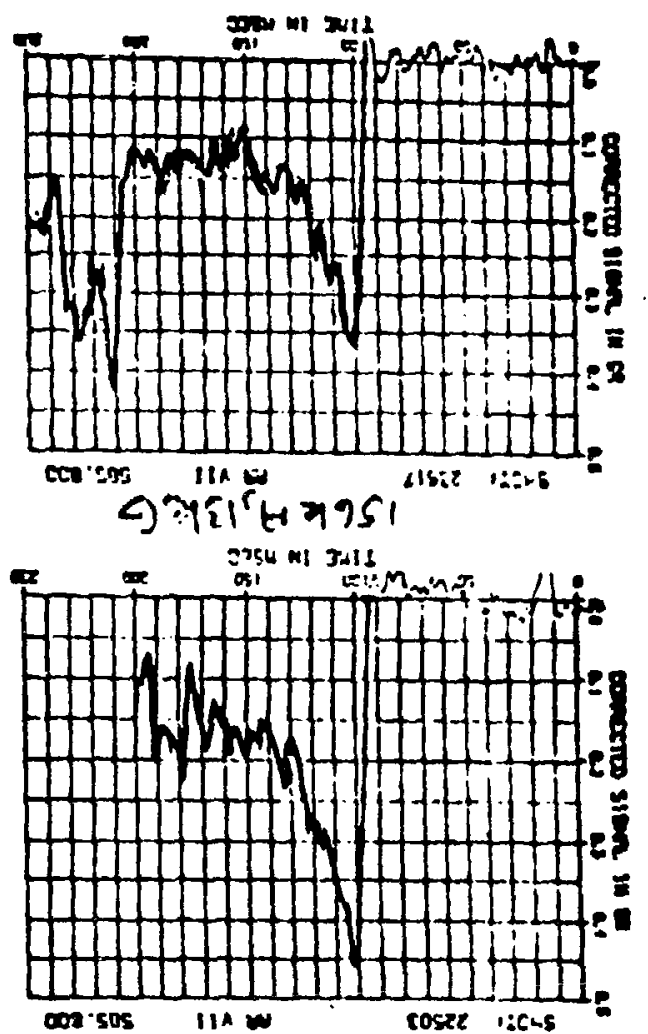

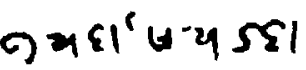
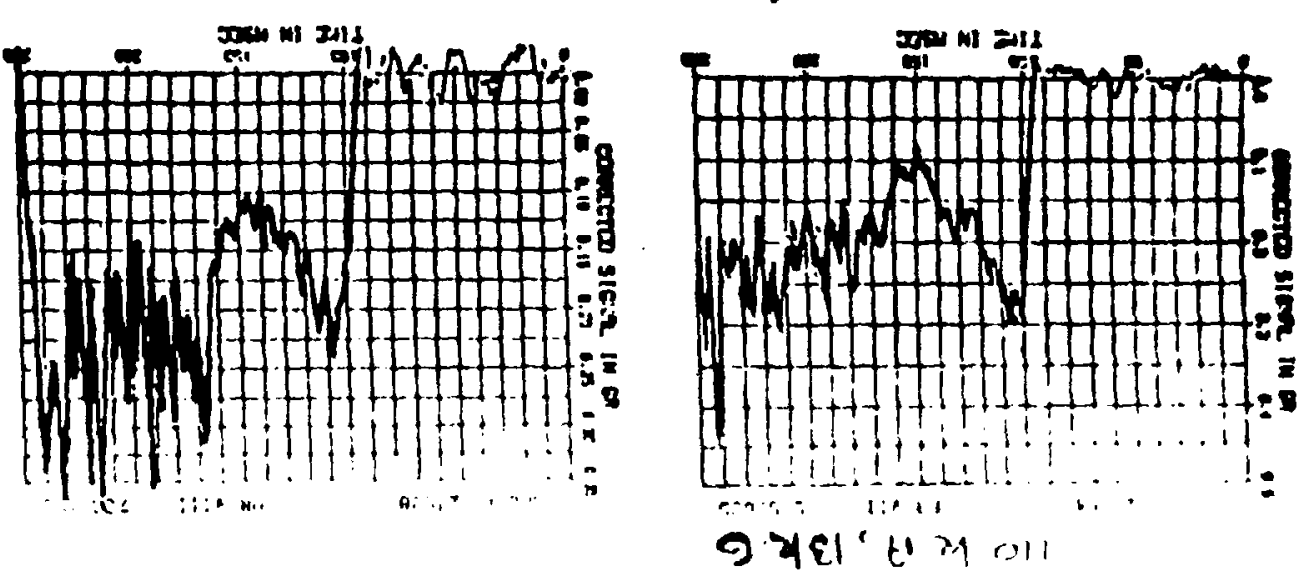
Confinement Times and

Transport Coefficients

Near Density Limits 
Neoclassical Impurity Transporits

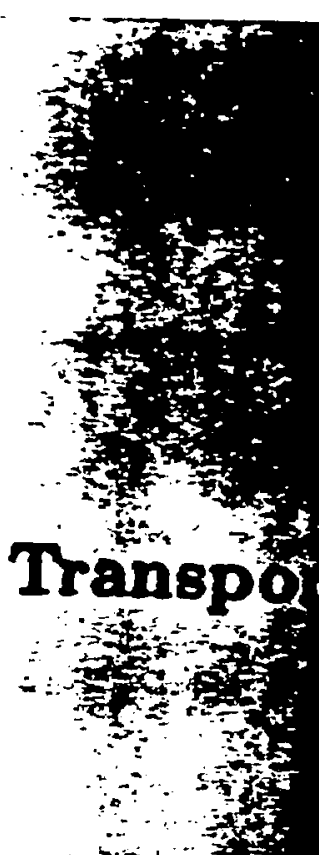

finement "Observation of Long Impurs K.H. Burrell et al. - NF 21 (1981) (i) .....it is found that both impurity peretit
times and impurity containment times are
with neoclassical predictions. ....it is found that both impurity perety
withes and impurity containment times are
weoclassical predictions.

3

\section{;}

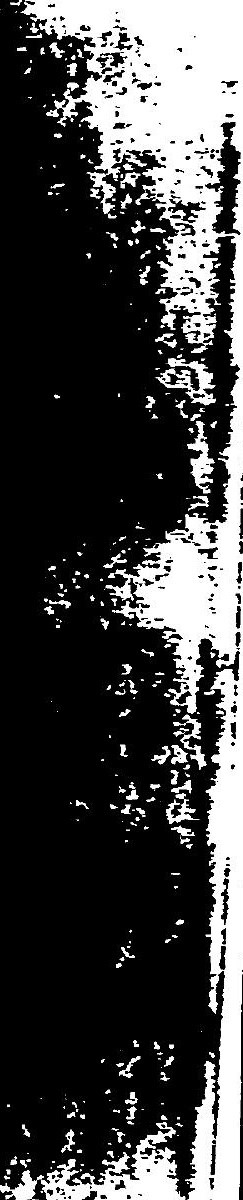


EMISSION RATE (GR) FMISSION RATE (OR) EMISENON RATE (OR) -
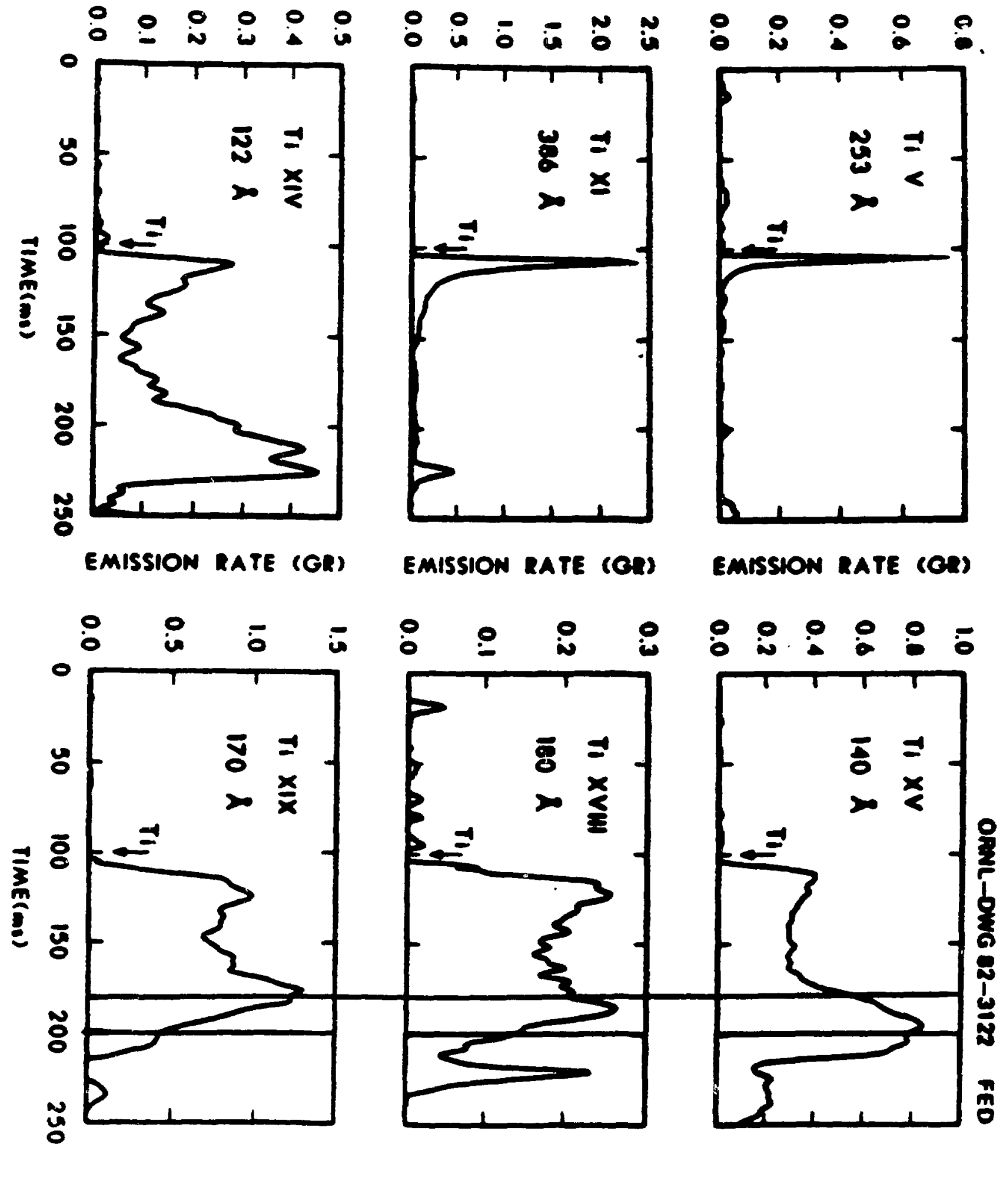

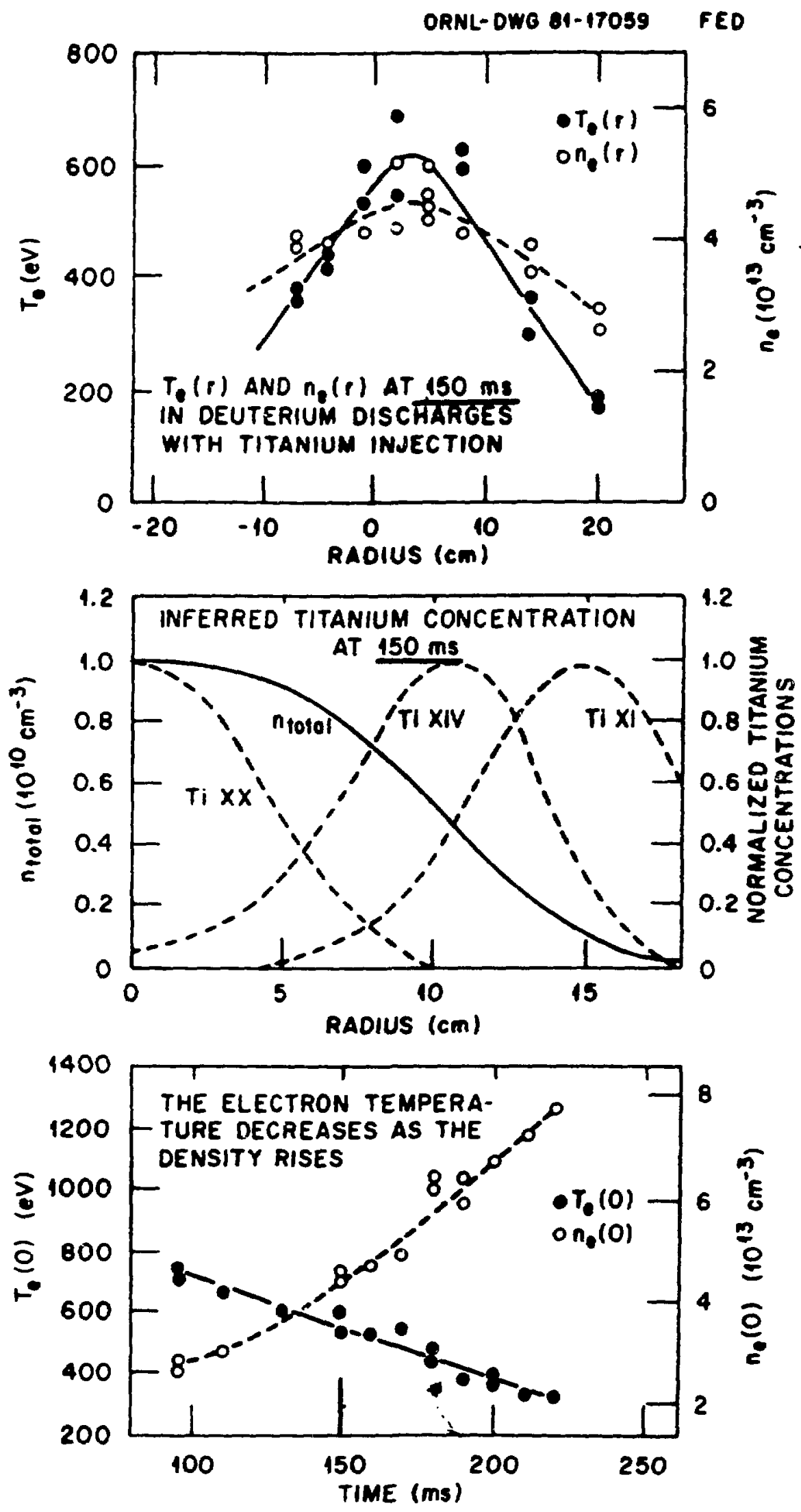
TEMPORAL EVOLUTION OF TITANIUM EMISSION AFTER TRANSPORT EOUILIBRIUM IS ESTABLISHED
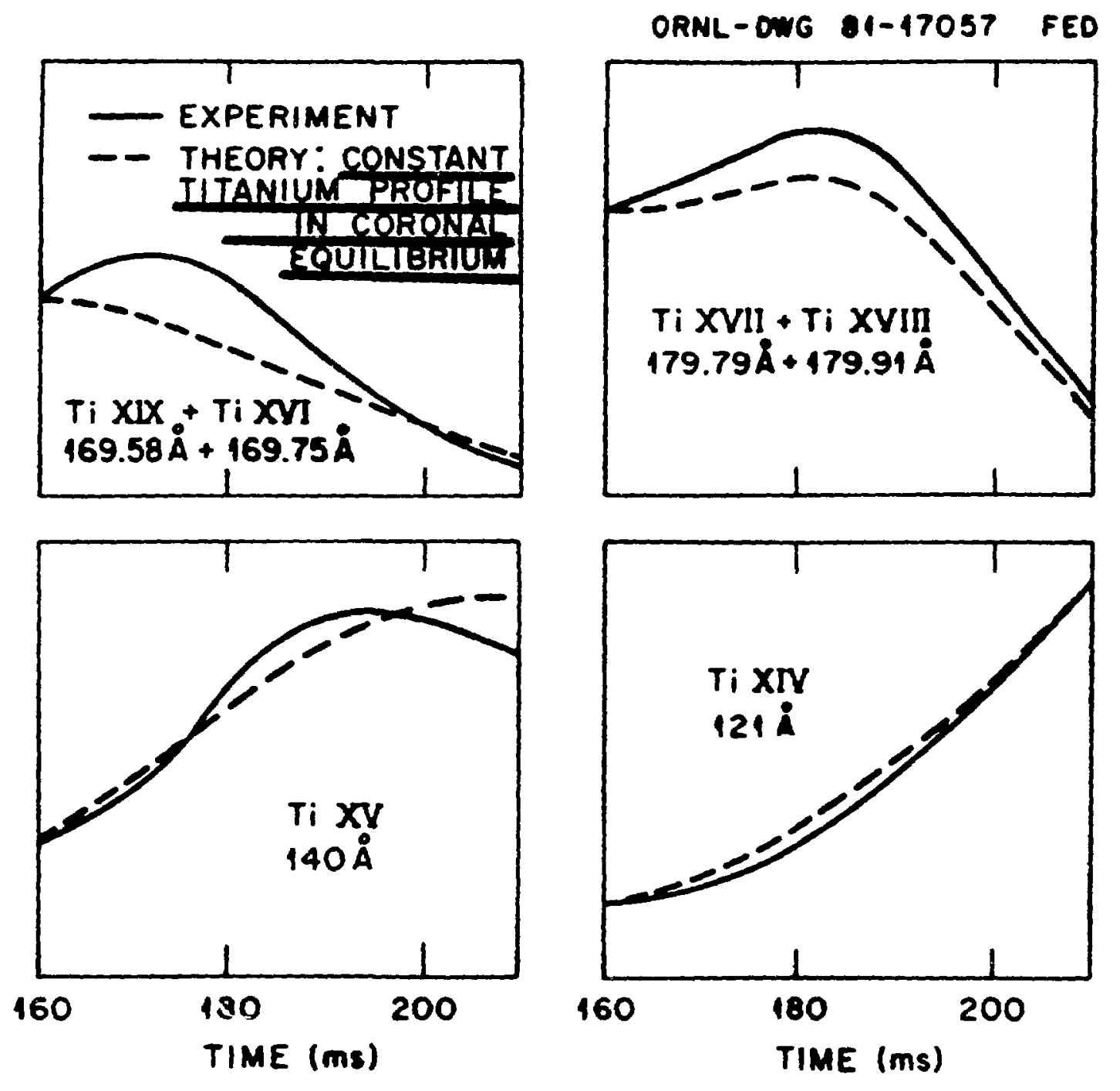
EMPIRICAL DESCRIPTIONS OF IMPURITY TRANSPORT

$$
\begin{gathered}
\frac{\partial N^{\prime}}{\partial t}+\nabla \cdot \Gamma^{2}=Q \\
I_{r}^{\prime}=-D(r) \frac{\partial N^{\prime}}{\partial r}-V_{0} f(r) N^{\prime}
\end{gathered}
$$

IF $\mathrm{D}=$ CONSTANT

AND $f(r)=\frac{r}{a l}=$

THE TDEE DEPENDENT SOLUTIONS ARE

$$
N^{I}=\Sigma C_{n} e^{\frac{-1}{\cdots} e^{-S \rho^{2}} M}\left(-\frac{\lambda_{n} a_{l}^{2}}{4 S D}, 1, S \rho^{2}\right)
$$

WHERE $s=\frac{e v}{2 D}, \lambda=\frac{1}{r_{0}}$, AND $M=$ THE CONFLUENT HYPERGEOMETRIC FUNC TION.

THE STEADY STATE SOLUTION $\left(r_{r}^{\prime}=0\right)$ IS

$$
N_{1}=N_{1}(0) \exp \left[-\frac{V_{o \rho^{2}}}{2 D a_{l}}\right]=N^{l} e^{-s \rho^{2}}
$$

THIS RESULT DMPLIES THAT THE INTRINSIC DMPURITY LEVEL IS STRONGLY PEAKED AT $\rho=0$ if $\frac{V_{0}}{D}$ IS LARGE.

$N$, IS UNIFORM AS A FUNCTION OF , F CONVECTION IS NEGLIGIBLE COMPARED TO DIFFUSION. 


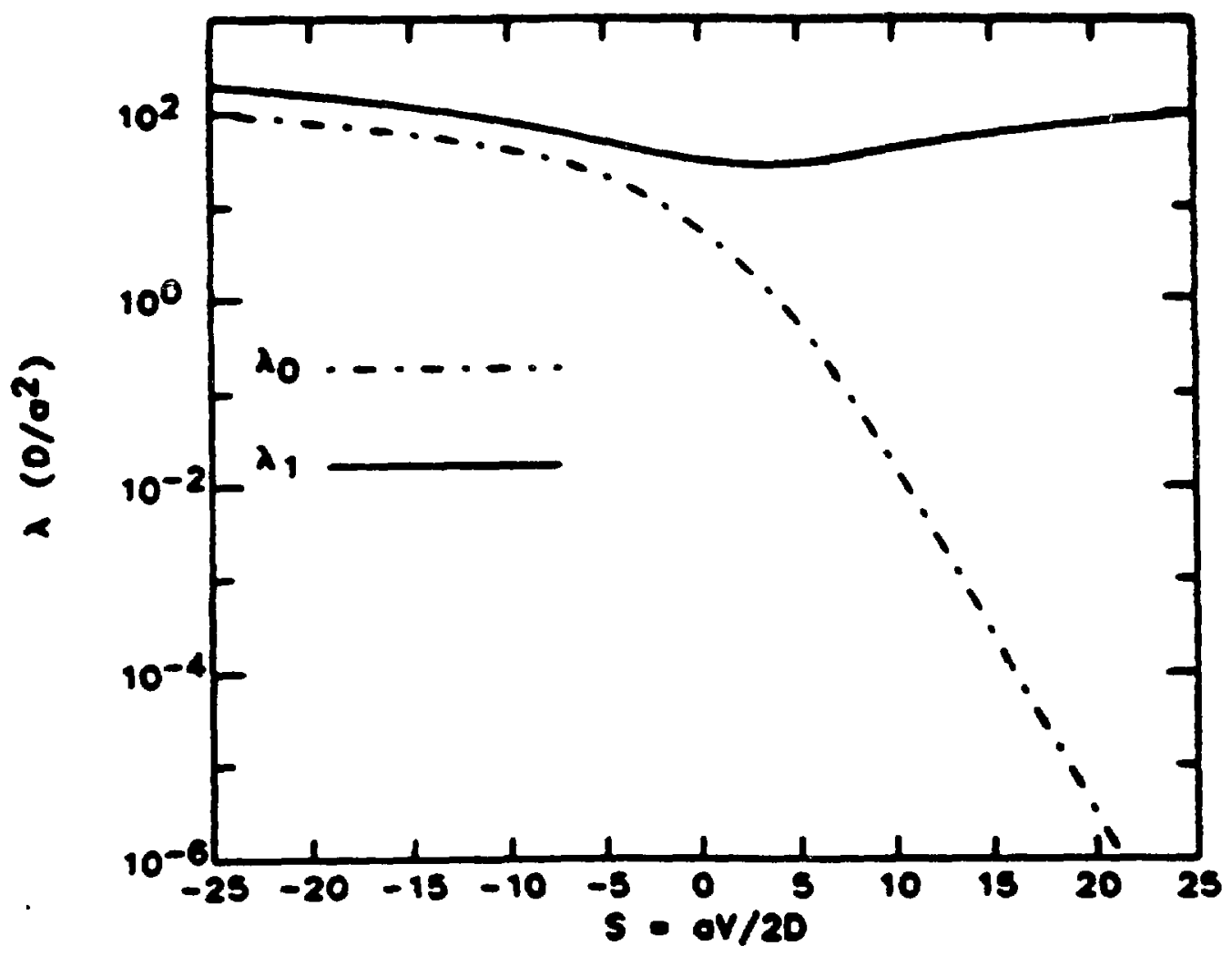

TITANIUM DISTRIBUTION AT 150 MS SOUD - MODELING OF SPECTRAL INTENSITIES DASH - GAUSSIAN DISTRIBUTION

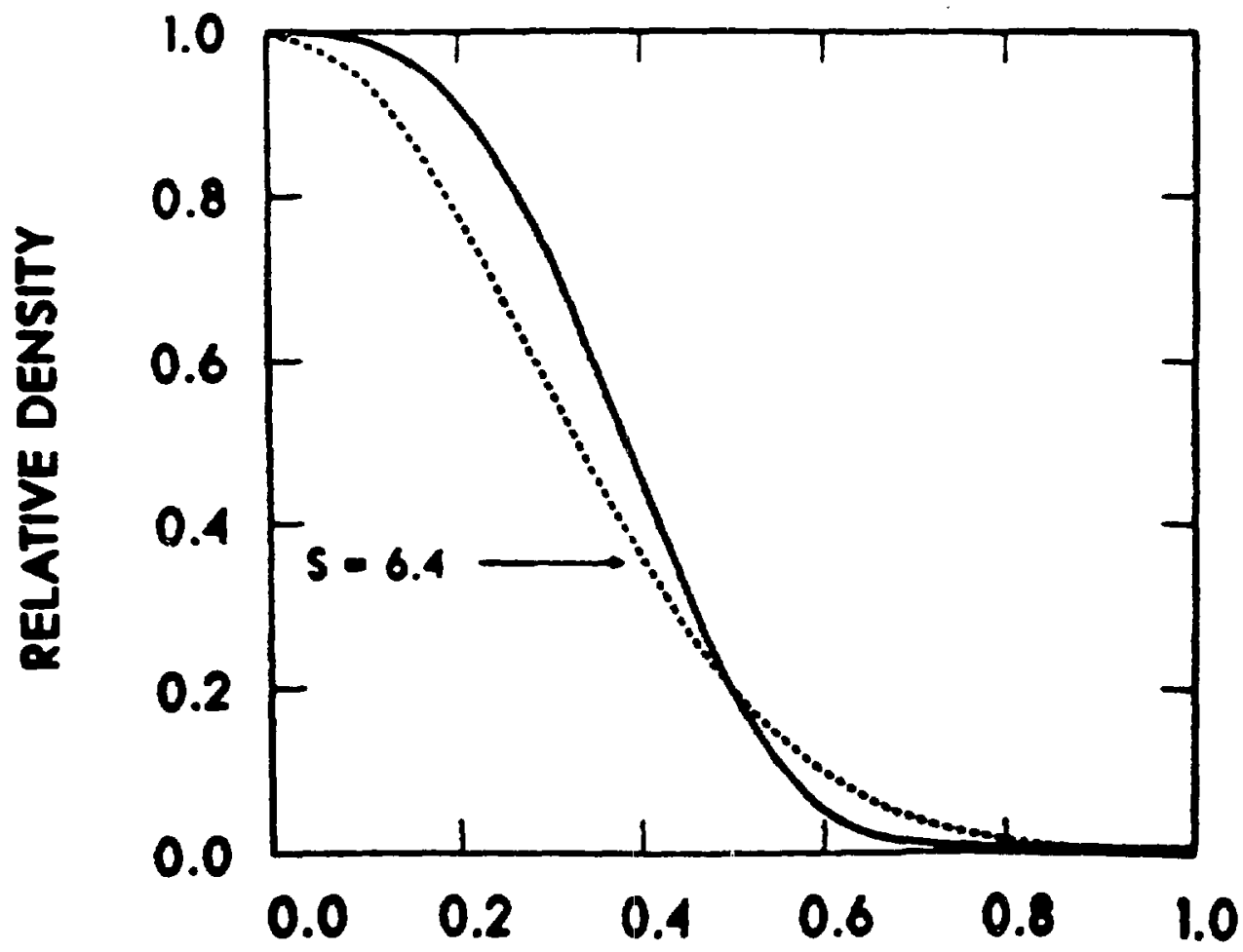




\section{ANALYSIS OF TITANIUM INJECTION EXPLRIMENTS ON ISX-B WITH DEUTERIUM AS THE WORKING GAS}

TAKE $S=6.4$ TO GIVE AN ACCEPTABLE MATCH BETWEEN THE PROFILE DETERMINED FROM SPECTROSCOPY AND THE GAUSSUN exp $\left[-s^{2}\right]$.

$$
\begin{aligned}
& \frac{V_{0 Q C l}}{2 D}=6.4 \\
& V_{0}=0.48 D
\end{aligned}
$$

ASSUME THE RISE TDME OF THE Ti XDX SIGNAL (0.020 S) EQUALS $r_{1}$.

$$
\begin{gathered}
\tau_{1}=\gamma \frac{a_{l}^{2}}{D} \\
\gamma \simeq 0.05 \text { for S }=0.4\left(\text { FROM GRAPH OF } \lambda_{1}\right) \\
\frac{D=1.8 \times 10^{3} \mathrm{~cm}^{2} / \mathrm{s}}{V_{0}=800 \mathrm{em} / \mathrm{S}\left(\text { FROM GRAPB OF } \lambda_{0}\right)} \\
\frac{\tau_{0}=3.1 \mathrm{~S} !}{}
\end{gathered}
$$

AS EXPECTED FROM THESE NUMBERS, TYPICAL ISX-B OB DISCHARGES IN DEUTERIUM EVIDENCE ACCUMULATION OF INTRINSIC DMPURITIES.

THE COMBINATION OF TEXT AND ISX-B DATA SHOWS THAT THE MMPU. RITY CONFINEMENT TDME CAN CHANGE BY A FACTOR OF 100 FOR CHANGES OF LESS THAN A FACTOR OF 2 IN $B_{T}, I_{p}$, or $N_{e}$. 


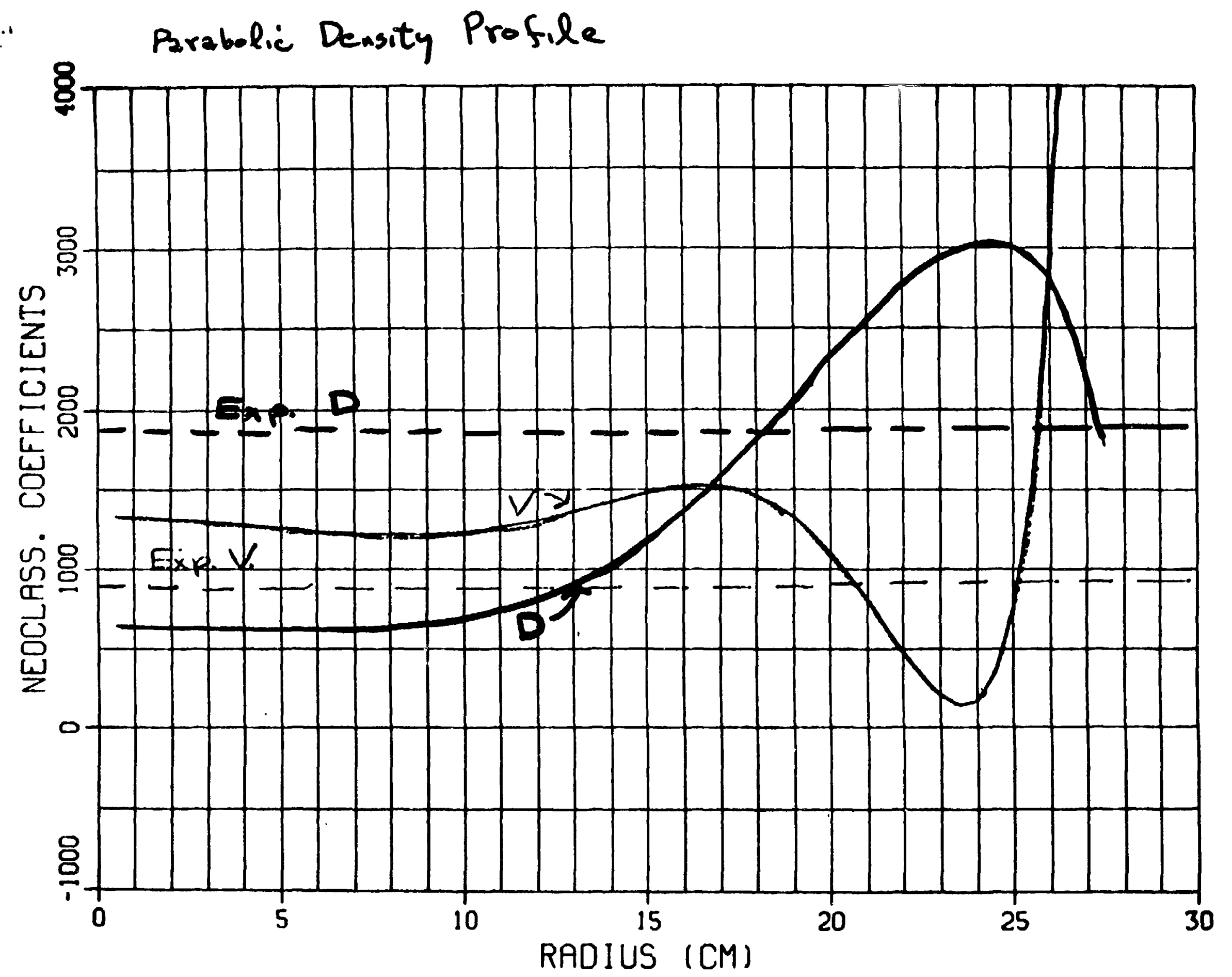

Neoclassical Transport Coefficients 


\section{Evidence of Long Confinement Times Near Density Limits in ASDEX, T-10, and TEXTOR}




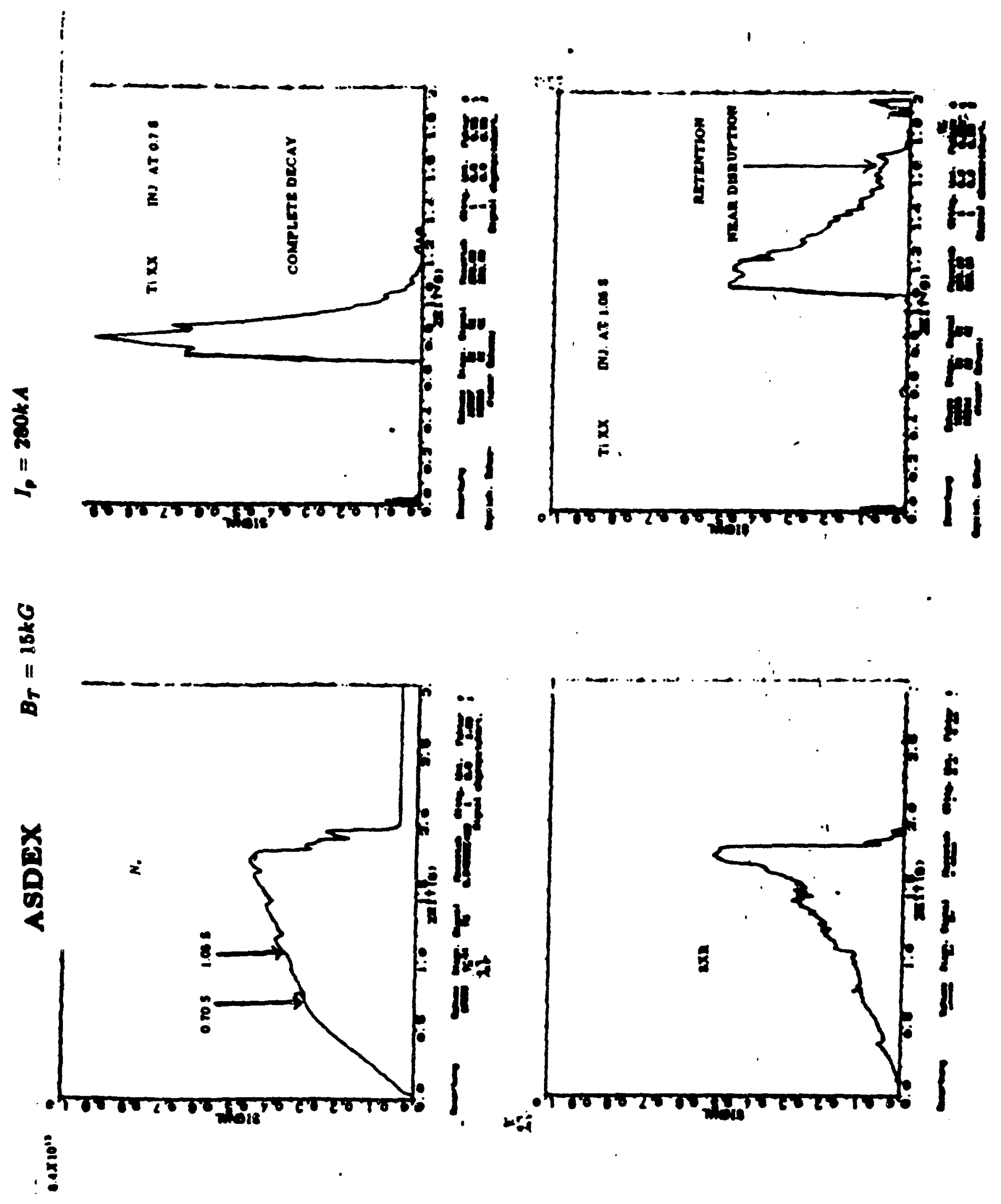




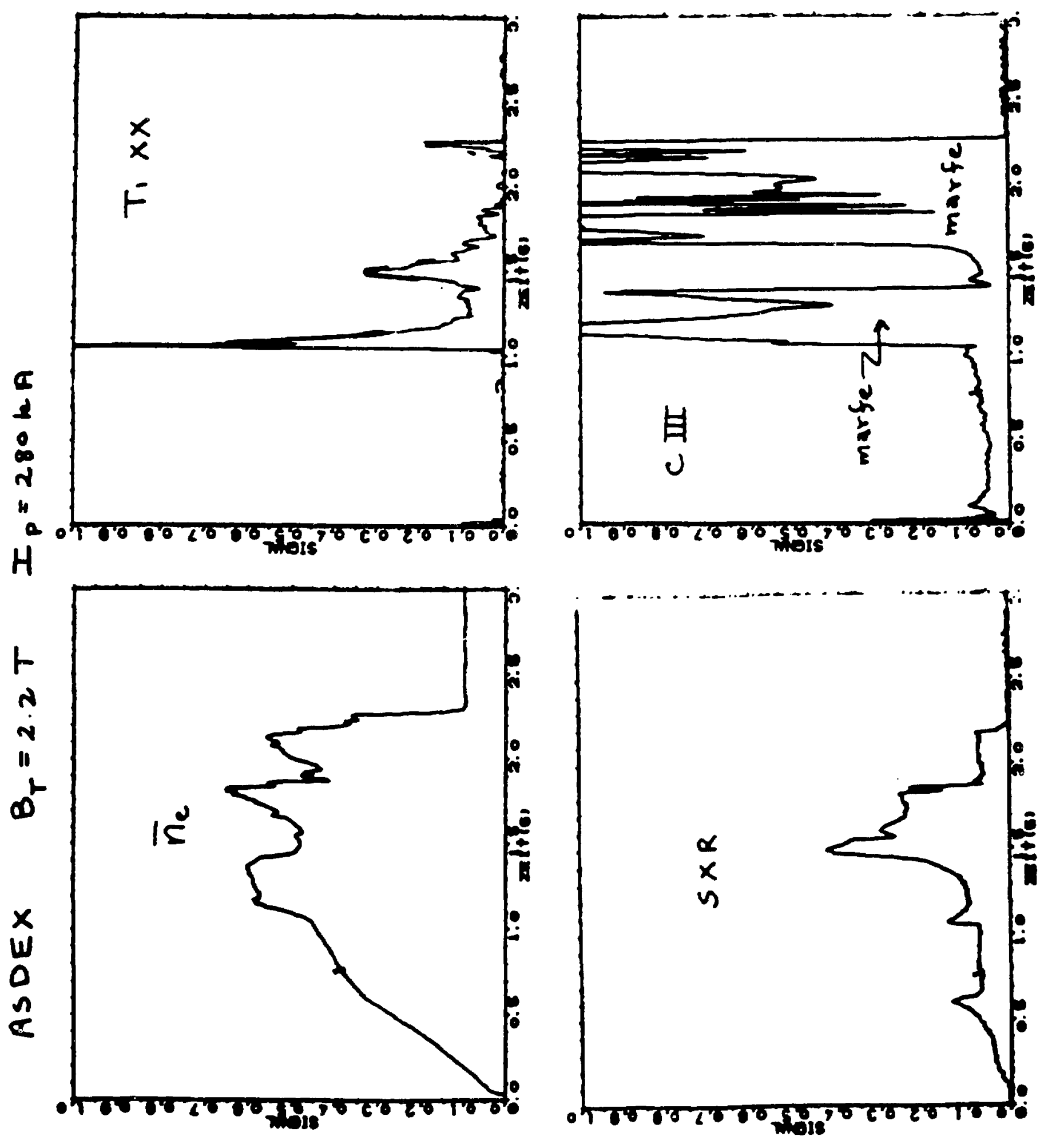




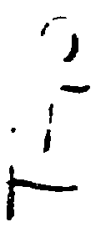

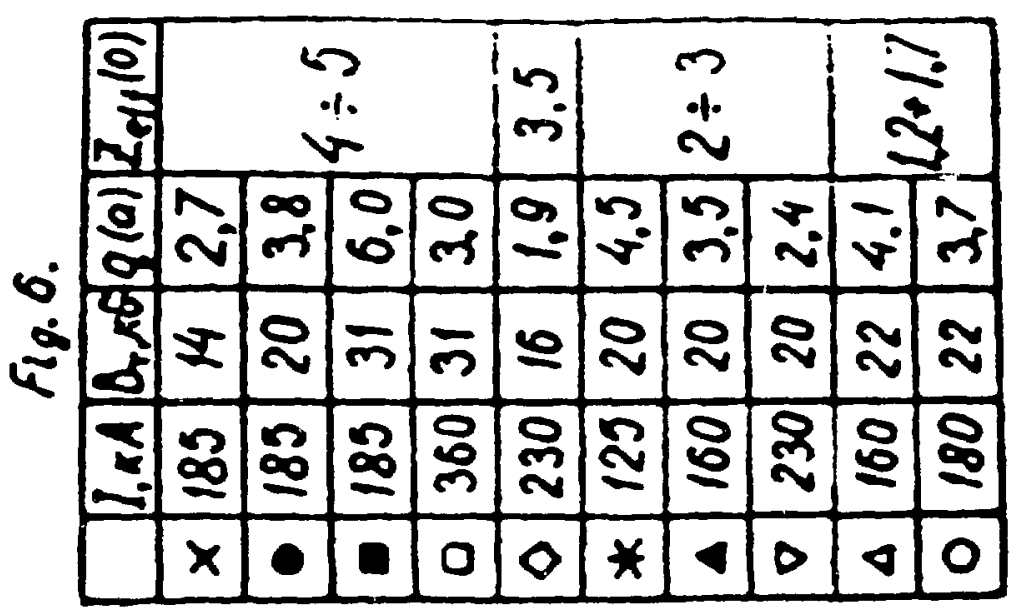

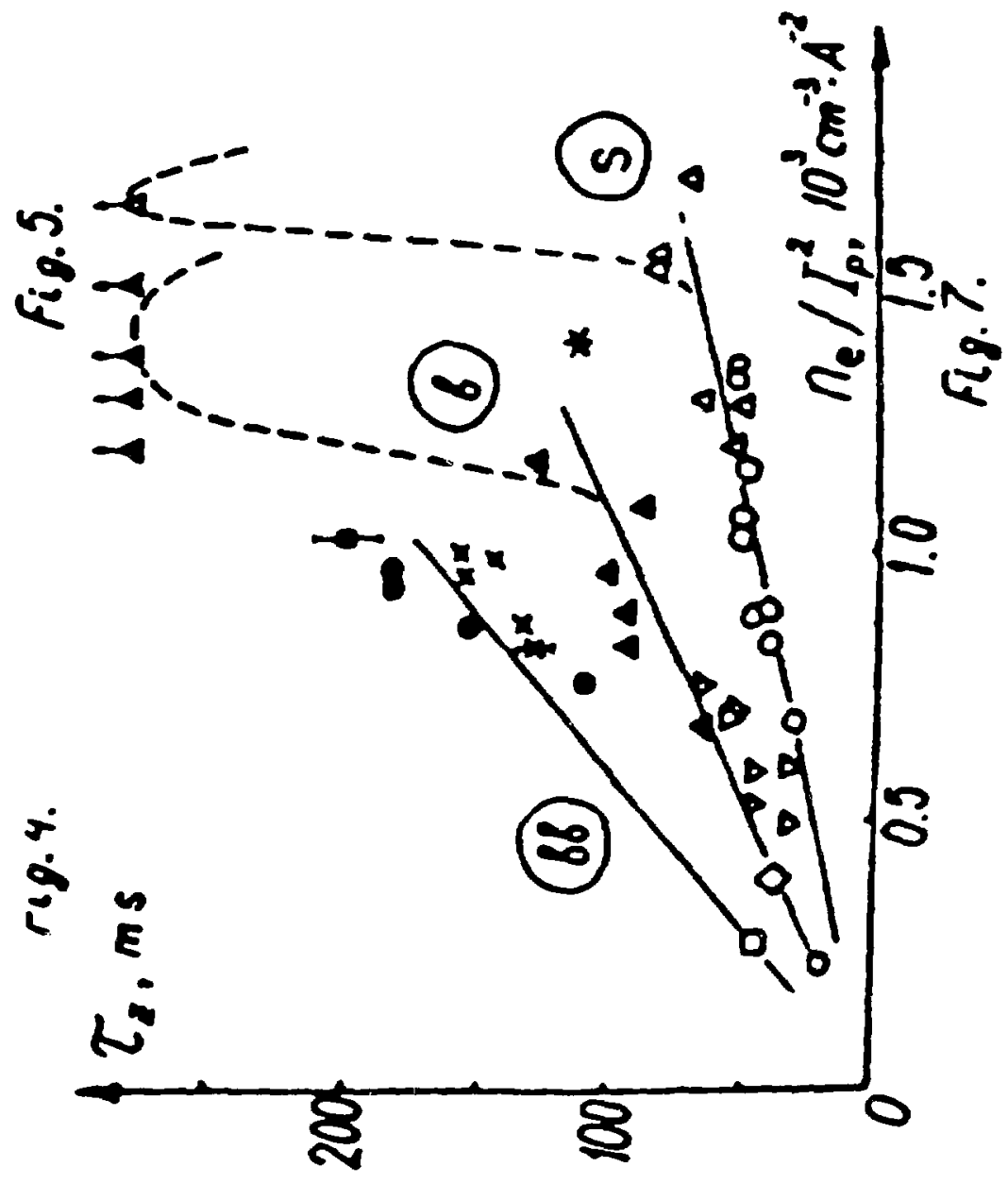




\section{TEXTOR}

Castracane et al.
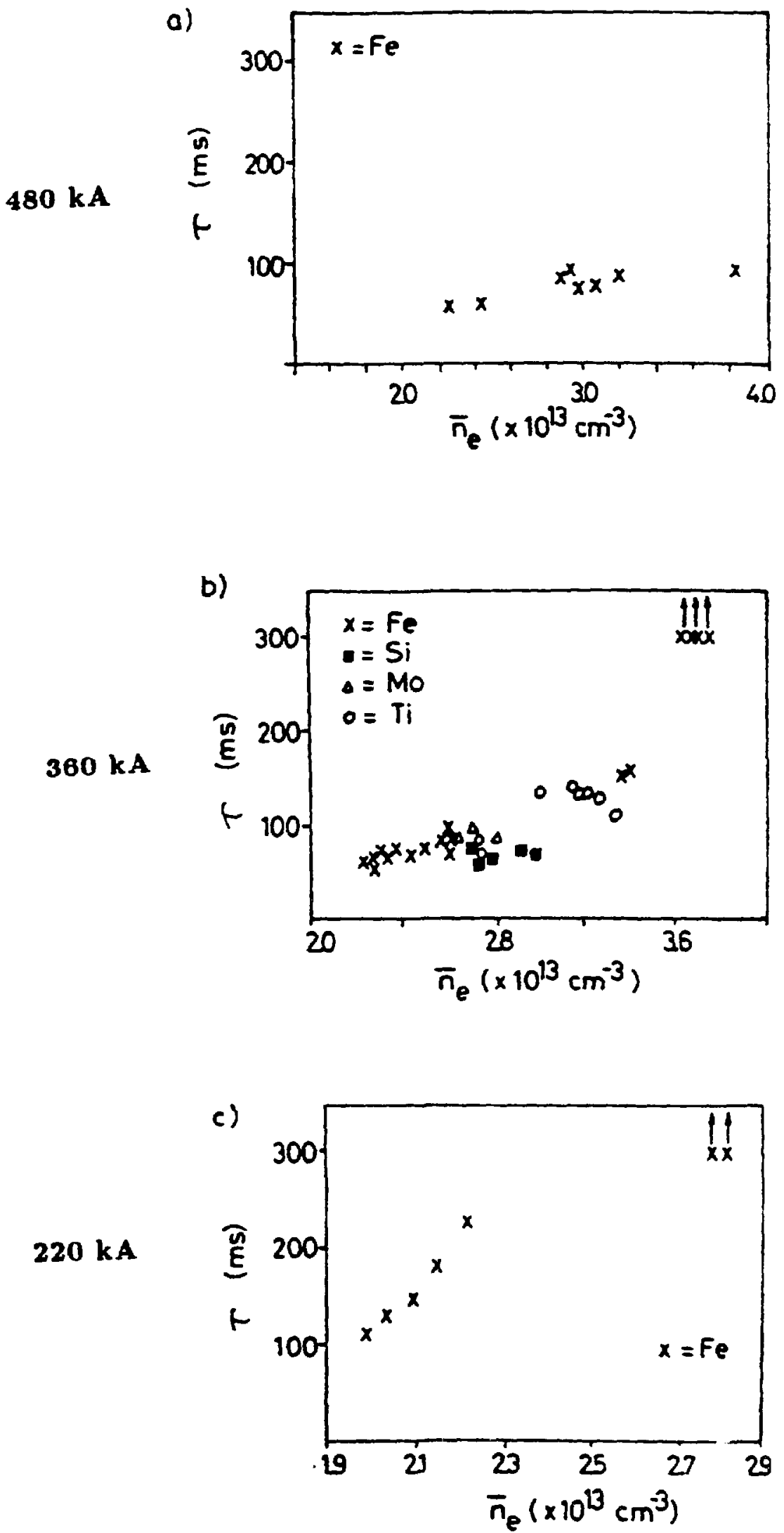


\section{SUMMARY}

- ANOMALOUS DIFFUSION OF IMPURITIES (AND POSSIBLY THE WORKING GAS) IS SUPRESSED IN THE INTERIOR OF TOKAMK PLASMAS NEAR DENSITY LIMITS. INWARD CONVECTION THEN RESULTS IN RETENTION OF INJECTED TEST IMPURITIES.

- THIS CHANGE TO CONVECTION DOMINATED TRANSPORT OFTEN RESULTS OFTEN RESULTS IN THE ACCUMULATION OF INTRINSIC IMPURITIES, AT LEAST ABOVE $q \approx 3$. IF SO, A THERMAL COLLAPSE AT THE CENTER INITIATES A PARTIAL DISRUPTION.

- SHARP INCREASES IN $\tau_{z}$ ARE ALSO OBSERVED BEFORE MAJOR DISRUPTIONS. THE ROLE OF ENHANCED IMPURITY CONFINEMENT IN INITIATING SUCH DISRUPTIONS IS UNCERTAIN. 
- FURTHER DOCUMENTATION OF $\tau_{z}$ IN DISRUPTIVE DISCHARGES COULD BE ENLIGHTENING FOR UNDERSTANDING DENSITY LIMITS. ALSO, CHANGES OF IMPURITY TRANSPORT NEAR DENSITY LIMITS IN AUXILLIARY HEATED DISCHARGES HAVE NOT BEEN STUDIED.

\section{DISCLAIMER}

This report was prepared as an account of work sponsored by an agency of the United States Government. Neither the United States Government nor any agency thereof, nor any of their employees, makes any warranty, express or implied, or assumes any legal liability or responsibility for the accuracy, completeness, or usefulness of any information, apparatus, product, or process disclosed, or represents that its use would not infringe privately owned rights. Reference herein to any specific commercial product, process, or service by trade name, trademark, manufacturer, or otherwise does not necessarily constitute or inply its endorsement, recommendation, or favoring by the United States Government or any agency thereof. The views and opinions of authors expressed herein do not necessarily state or reflect those of the United States Government or any agency thereof. 